\title{
Novel Imaging Modalities Shedding Light on Plant Biology: Start Small and Grow Big
}

Natalie M. Clark,,${ }^{1,2}$ Lisa Van den Broeck, ${ }^{1, *}$ Marjorie Guichard, ${ }^{3,4}$ Adam Stager, ${ }^{5}$ Herbert G. Tanner, ${ }^{5}$ Ikram Blilou, ${ }^{6}$ Guido Grossmann, ${ }^{3,4}$ Anjali S. Iyer-Pascuzzi, ${ }^{7}$ Alexis Maizel, ${ }^{3}$ Erin E. Sparks,${ }^{8}$ and Rosangela Sozzani ${ }^{1}$

${ }^{1}$ Department of Plant and Microbial Biology, North Carolina State University, Raleigh, North Carolina 27695,USA; email: nmclark2@iastate.edu, lfvanden@ncsu.edu,rsozzan@ncsu.edu ${ }^{2}$ Department of Plant Pathology and Microbiology, Iowa State University, Ames, Iowa 50010, USA

${ }^{3}$ Center for Organismal Studies (COS), University of Heidelberg, 69120 Heidelberg, Germany; email: marjorie.guichard@cos.uni-heidelberg.de, guido.grossmann@cos.uni-heidelberg.de, alexismaizel@cos.uni-heidelberg.de

${ }^{4}$ CellNetworks Cluster of Excellence, Heidelberg University, 69120 Heidelberg, Germany

${ }^{5}$ Department of Mechanical Engineering, University of Delaware, Newark, Delaware 19711, USA; email: astager@udel.edu,btanner@udel.edu

${ }^{6}$ Department of Plant Cell and Developmental Biology, Biological and Environmental Sciences and Engineering (BESE), King Abdullah University of Science and Technology (KAUST), Thuwal 23955, Saudi Arabia; email: ikram.blilou@kaust.edu.sa

${ }^{7}$ Department of Botany and Plant Pathology and Center for Plant Biology, Purdue University, West Lafayette, Indiana 47907, USA; email: asi2@purdue.edu

${ }^{8}$ Department of Plant and Soil Sciences and the Delaware Biotechnology Institute, Newark, Delaware 19711,USA; email: esparks@udel.edu

\section{Keywords}

Förster resonance energy transfer, scanning fluorescent correlation spectroscopy, microfluid devices, light sheet microscopy, imaging of macroscopic traits, multiscale imaging techniques 
This manuscript has been accepted in Annual Reviews of Plant Biology (ARPB). This version has not undergone final editing. Please refer to the final version at the ARPB.

\begin{abstract}
The acquisition of quantitative information on plant development across a range of temporal and spatial scales is essential to understand the mechanisms of plant growth. Recent years have shown the emergence of imaging methodologies that enable the capture and analysis of plant growth, from the dynamics of molecules within cells to the measurement of morphometric and physiological traits in field-grown plants. In some instances, these imaging methods can be parallelized across multiple samples to increase throughput. When high throughput is combined with high temporal and spatial resolution, the resulting image-derived data sets could be combined with molecular large-scale data sets to enable unprecedented systems-level computational modeling. Such image-driven functional genomics studies may be expected to appear at an accelerating rate in the near future given the early success of the foundational efforts reviewed here. We present new imaging modalities and review how they have enabled a better understanding of plant growth from the microscopic to the macroscopic scale.
\end{abstract}

\title{
INTRODUCTION
}

Many important biological processes within an organism occur on different spatial and temporal scales. For example, cell division is triggered by specific gene and protein networks. As cells divide, they form larger tissues and organs that can be influenced by external factors, such as chemical and physical conditions or biological interactions. To better understand how these processes proceed over different spatial scales, researchers have developed imaging methods that range from microscopic intra- and intercellular interactions to mesoscopic tissue- and organ-level processes to the macroscopic scale, including whole organisms or even populations. Some of these imaging techniques can continuously sample at an appropriate rate and in response to variations in experimental conditions, which enables the quantification of the dynamics of developmental processes. For example, live imaging (imaging the activity as it is occurring) provides unprecedented levels of temporal detail that encompass the study of plant biology, including tissue patterning, cell division, cell specification, hormone distribution, and plant architecture. Methods like fluorescence correlation spectroscopy (FCS) (3ㅡ), Förster resonance energy transfer coupled with fluorescence lifetime imaging (FRET-FLIM)i $(\underline{164})$, and superresolution microscopy (136) have been developed to study molecular dynamics within a single 
This manuscript has been accepted in Annual Reviews of Plant Biology (ARPB). This version has not undergone final editing. Please refer to the final version at the ARPB.

cell, such as protein binding, as well as between different cells, such as protein movement

(Figure 1). Moving to a larger scale, methods such as magnetic resonance imaging (MRI) fluorescence molecular tomography ${ }^{\mathrm{iii}}$ (FMT), X-ray microcomputed tomography $(\mu \mathrm{CT})$, positron emission tomography (PET), and ultrasound have been used to obtain images of whole organs

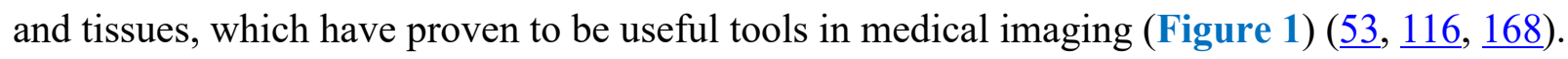
The combination of data from these imaging modalities draws an integrated picture of plant biology, from the single cell to the entire organism. On an even larger scale, new techniques have been developed, allowing for quantitative imaging of entire plant populations. These macroscale techniques are especially important for surveying crop quality and determining how environmental conditions impact yield (Figure 1).

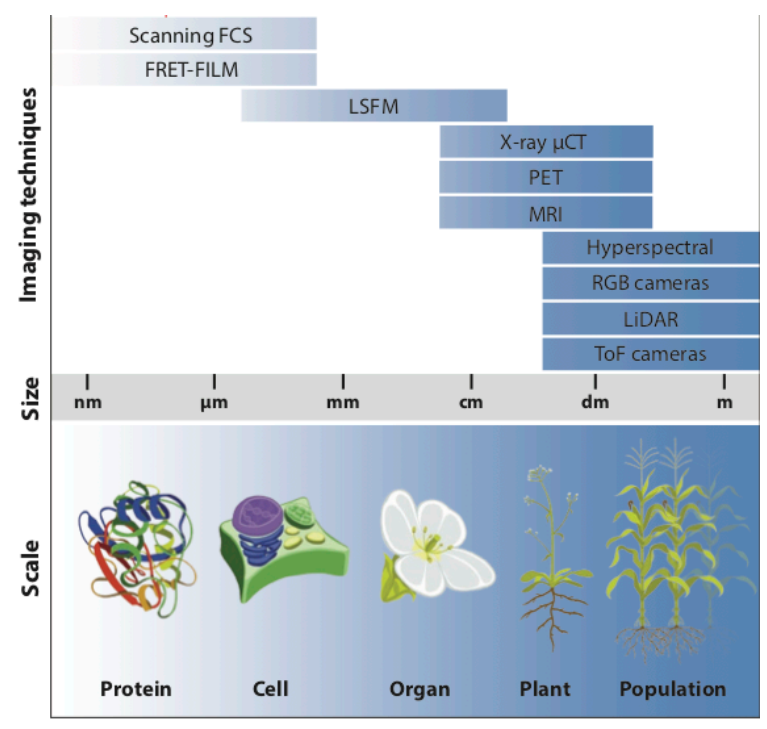

Figure 1 Imaging modalities for image analysis across microscopic, mesoscopic, and macroscopic scales. At the microscopic scale, FRET-FLIM visualizes the dynamics and localization of protein interactions. Compatible with FRET-FLIM, scanning FCS analyzes complex stoichiometry but is also able to analyze protein oligomerization and protein movement. On the mesoscopic scale, LSFM allows imaging of cells in tissues and organs over extended periods of time. MRI, X-ray $\mu \mathrm{CT}$, and PET can nondestructively image whole root systems. RGB cameras, multispectral and hyperspectral cameras, ToF cameras, and LiDAR sensors allow for the nondestructive imaging of shoots of single plants or whole populations. Abbreviations: FRET-FLIM, Förster resonance energy transfer with fluorescence lifetime imaging microscopy; scanning FCS, scanning fluorescence correlation spectroscopy; LSFM, light sheet fluorescence microscopy; MRI, magnetic resonance imaging; X-ray $\mu \mathrm{CT}$, X-ray microcomputed tomography; PET, positron emission tomography; RGB, red, green, and blue; ToF, time of flight; LiDAR, light detection and ranging. 
This manuscript has been accepted in Annual Reviews of Plant Biology (ARPB). This version has not undergone final editing. Please refer to the final version at the ARPB.

While most imaging techniques had their original applications in animal systems, many have been adapted to plants $(\underline{130})$. Here, we describe recent imaging techniques that have been successfully used to analyze plant biology on increasing spatial scales, ranging from microscopic to mesoscopic and macroscopic (Figure 1). Starting at the molecular level, we detail how FRETFLIM and scanning fluorescence correlation spectroscopy (FCS) ${ }^{\text {iv }}$ methods have been used to quantify protein interactions and movement in vivo within different plant cell types. Next, at the mesoscopic scale, we present methods that either monitor cellular events in the context of whole growing organs with light sheet fluorescence microscopy $(\mathrm{LSFM})^{\mathrm{v}}$ or image tissues from multiple plants simultaneously under controlled environmental conditions using microfluidics devices. Finally, at the macroscopic scale, we present methods used to image entire plant organs or even different populations of plants grown together in a field. Techniques such as PET, X-ray $\mu \mathrm{CT}$, and MRI imaging, co-opted from the medical imaging field, have been used to noninvasively study root systems growing in soil. Additionally, we detail how ultrasound, infrared imaging, and light detection and ranging (LiDAR) ${ }^{\mathrm{vi}}$ have been coupled with technologies such as unmanned aerial vehicles to allow for high-throughput imaging of entire plant populations. Looking to the future, we believe that developing methodologies that combine multiscale imaging data will allow for a more accurate picture of how biological processes occur over space and time within and across organisms.

\section{FRET-FLIM AND SCANNING FCS AS TOOLS TO DETERMINE PROTEIN DYNAMICS AT CELLULAR RESOLUTION}

Fluorescence microscopy is an essential tool in cell biology. The use of fluorescence imaging technologies has contributed tremendously to solving biological questions such as the visualization of tissue dynamics and morphogenesis, determination of subcellular localization, changes in protein turnover in time and space and under different stimuli, and formation and stoichiometry of protein complexes. In the last 25 years, the performance of fluorescence imaging has increased dramatically in the biological sciences, especially with the new generation of confocal microscopes equipped with higher-sensitivity detectors and genetic engineering advances in generating fluorophores with higher brightness, improved quantum yield and fluorescence lifetime, and increased sensitivity $(\underline{11}, \underline{51}, \underline{52}, \underline{140})$. With these tools, in vivo imaging can be implemented noninvasively and as a routine technology. A great example is the 
This manuscript has been accepted in Annual Reviews of Plant Biology (ARPB). This version has not undergone final editing. Please refer to the final version at the ARPB.

determination of subcellular protein localization within living cells and at high resolution in a living organism $(\underline{60}, \underline{84}, \underline{85})$.

In 1946, Theodor Förster introduced Förster resonance energy transfer (FRET) (느). FRET describes the phenomena in which, upon excitation, energy is transferred from a donor fluorophore to an acceptor fluorophore present within a range of 1-10 nm. FRET occurrence results in a decrease in the intensity of the donor's fluorescence and an increase in the acceptor's fluorescence intensity. FRET can also be measured by determining the lifetime of the donor fluorophore using fluorescence lifetime imaging microscopy (FLIM) (24). The fluorescence lifetime can be described as the average time that a molecule stays in an excited state prior to its return to the ground state. The fluorophore lifetime can be displayed as images, which include the spatial distribution of excited-state lifetimes (19). During measurements, FLIM images are taken and lifetime values can be extracted by analyzing a region of interest (ROI) drawn within a pseudocolor lifetime map. Interactions can then be detected by measuring changes in the lifetime between ROIs within the same cell, tissue, or organ. These continuous advances allow the detection of protein localization as well as its physical association with relevant partners with a high spatial and temporal resolution, with high specificity, and without perturbing cell state, making it possible to follow protein association at the subcellular resolution in living multicellular organisms.

In plant tissues, FRET-FLIM has been widely used to validate, detect, and visualize protein interactions (Figure 2), especially with the increasing amount of protein interactions identified by yeast two-hybrid screens or mass spectrometry (MS)-based proteomics. Interactions of the MADS-box proteins were confirmed by FRET-FLIM in plant-derived protoplasts $(\underline{70}, \underline{71}, \underline{152})$. The plasmodesmata-localized reticulon (RTNLB) family proteins are additional examples of proteins identified by coimmunoprecipitation MS (ㅎ6). FRET-FLIM was also used to show homodimerization of the transcription factor family AUXIN RESPONSE FACTORs (ARFs), which have important roles in auxin response and plant growth and development (12), as well as heterodimerization with auxin/indole-3-acetic acid (AUX/IAA) proteins (e.g., ARF9 and IAA10) (120). In the case of receptor kinases, implementation of FRET-FLIM was insightful in showing that ARABIDOPSIS CRINKLY4 (ACR4) forms homomers and heteromers with CLAVATA 1 (CLV1) at the plasma membrane or in plasmodesmata in a concentration-dependent manner (144). FRET-FLIM analysis of the ligand-perceiving receptor for brassinosteroids, 
This manuscript has been accepted in Annual Reviews of Plant Biology (ARPB). This version has not undergone final editing. Please refer to the final version at the ARPB.

BRASSINOSTEROID INSENSITIVE 1 (BRI1) with its receptor SOMATIC

EMBRYOGENESIS RECEPTOR-LIKE KINASE (SERK3), revealed interactions at the plasma membrane in the epidermis of living Arabidopsis roots (13). Intriguingly, despite colocalization on the plasma membrane, interactions were detected only in a limited domain of the plasma membrane, indicating that only a small fraction of the BRI1 and SERK3 proteins are in close proximity $(\underline{13})$. In addition to resolving interactions with proteins involved in signaling processes within living tissues, FRET-FLIM was successfully used to detect transcription factor associations at cellular resolution in the Arabidopsis root meristem. Recent studies showed that the BIRD protein JACKDAW (C2H2-type transcription factor) forms a ternary complex with the mobile protein and cell fate regulator SHORTROOT (SHR) and its target SCARECROW (SCR) (91). Optimizing FRET-FLIM technology in living Arabidopsis roots showed that physical proximity between these proteins is cell-type dependent (91). These observations reflect the advantage of using this technology to detect differential protein associations within the same as well as between different subcellular compartments. 
This manuscript has been accepted in Annual Reviews of Plant Biology (ARPB). This version has not undergone final editing. Please refer to the final version at the ARPB.

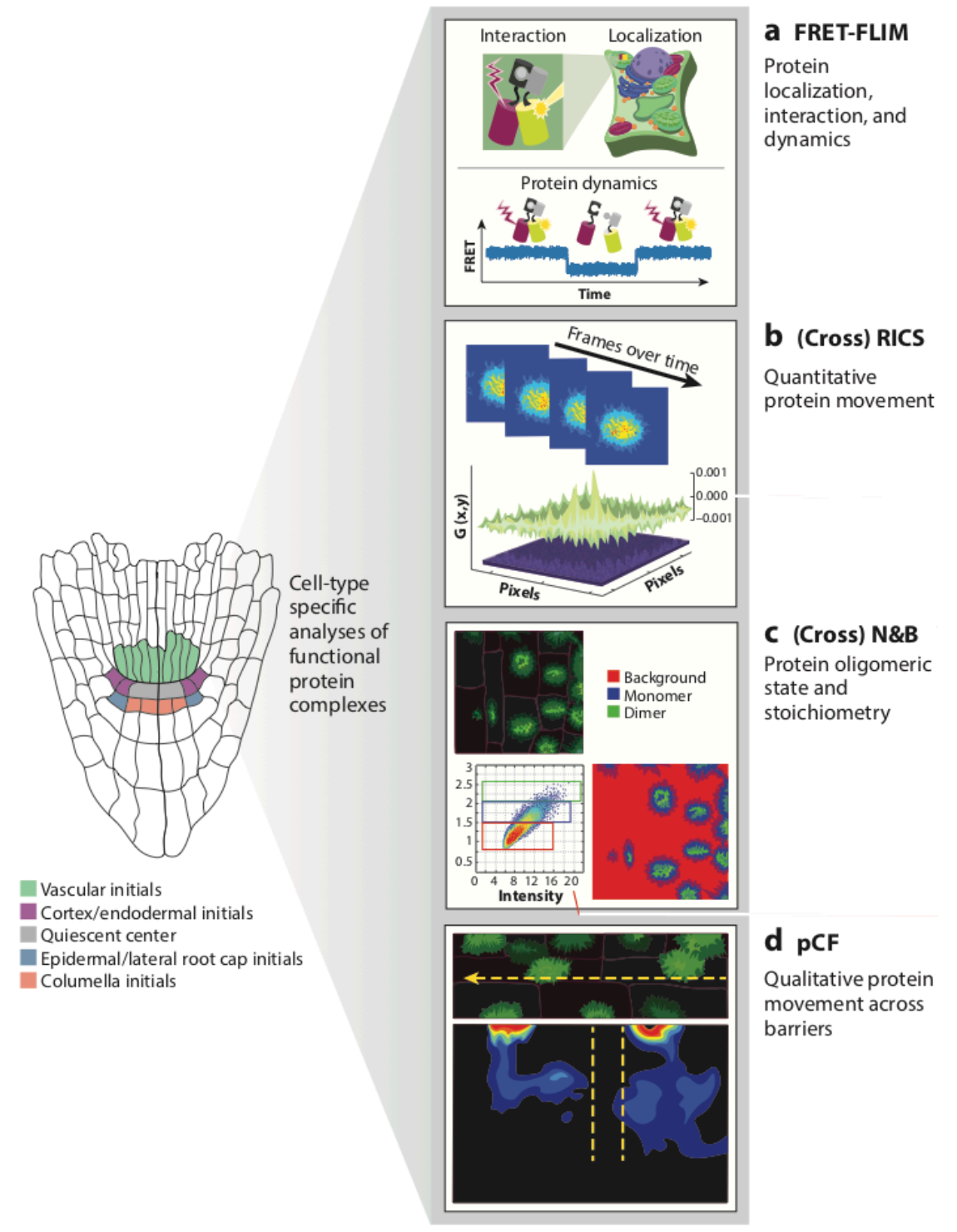

Figure 2 Applications of FRET-FLIM and scanning FCS to study intra- and intercellular molecular processes. (a)FRET-FLIM can be used to pinpoint the localization of proteins or protein interactions as well as to visualize the dynamics of protein interactions over time. (b) Within the field of scanning FCS, RICS and cross RICS can be applied to quantify movement of a single protein or a protein complex. (c) $\mathrm{N} \& \mathrm{~B}$ and cross $\mathrm{N} \& \mathrm{~B}$ can quantify the oligomeric state of a protein and the stoichiometry of a protein complex, respectively. (d) pCF analysis determines whether a protein moves across a barrier, such as a cell wall or nuclear envelope. Abbreviations: cross N\&B, cross-correlation number and brightness; FRET-FLIM, Förster resonance energy transfer with fluorescence lifetime imaging microscopy; scanning FCS, scanning fluorescence correlation spectroscopy; RICS, raster image correlation spectroscopy; $\mathrm{N} \& \mathrm{~B}$, number and brightness; $\mathrm{pCF}$, pairwise correlation function. 
This manuscript has been accepted in Annual Reviews of Plant Biology (ARPB). This version has not undergone final editing. Please refer to the final version at the ARPB.

Another extension of FRET-FLIM techniques involves scanning FCS methodologies. Tagging a protein with a fluorescent molecule allows scanning FCS to detect and quantify the constant fluctuations in fluorescence and protein dynamics (그). Fluorescence fluctuations over time correlate with the movement or kinetics of the fluorescent molecule while the amplitude of the fluctuations correlates with the protein concentration $(\underline{32}, \underline{115}, \underline{124})$. Scanning FCS has been developed to determine the oligomeric state of a protein complex, quantify protein interactions, and map protein movement between and within cells. Although scanning FCS has mainly been used in the animal kingdom to quantify, for example, protein aggregates, an emerging role for scanning FCS in the plant kingdom has become apparent in the last few years $(\underline{106}, \underline{124})$. Rather than operating independently, proteins interact with each other to form functional complexes in order to exert their molecular roles during plant development. As such, the stability, activity, and functionality of a protein can depend on its interaction partner. Analyzing the composition or oligomeric state of a protein complex as well as the dynamics of the formed complexes is thus important in the study of plant development and possible through the development of scanning FCS methodologies. To measure the oligomerization state of single proteins and heterologous protein complexes, one can use scanning FCS in combination with number and brightness (N\&B) vii analysis (Figure 2) (31). For this, the protein of interest is tagged with a fluorescent molecule. By detecting fluorescence intensities over time with raster scan images, the average and variance of intensity can be measured and used to calculate the N\&B, i.e., the intrinsic intensity of the fluorescent molecule (37). N\&B allows for the detection of different oligomeric states of fluorescent-tagged proteins while taking into account immobile fluorescent-tagged proteins, autofluorescence, and bleaching in a living cell $(\underline{22}, \underline{31})$. If two proteins are tagged with different fluorophores [e.g., green fluorescent protein (GFP) and mCherry], N\&B can quantify protein complex stoichiometry based on the coinciding appearance of two fluorophores in a process called cross-correlation N\&B (cross N\&B) ${ }^{\text {viii }}$ or crosscorrelation FCS (Figure 2) $(\underline{4}, \underline{137})$. For cross N\&B, the fluctuations of fluorescence are calculated from the intensity measured over time from two or more detection channels, depending on the number of different fluorophores (62).

In the root stem cell niche of Arabidopsis thaliana, N\&B analyses have been used to determine the oligomeric state of several key regulators in stem cell maintenance $(\underline{20}, \underline{21})$. First, by analyzing raster images of specific stem cells in the root stem cell niche, one can determine 
This manuscript has been accepted in Annual Reviews of Plant Biology (ARPB). This version has not undergone final editing. Please refer to the final version at the ARPB.

the cell specificity and distribution of protein complexes and their oligomeric state. As such, the authors $(20,21)$ reported that the stoichiometry, as well as the abundance of the well-known SHR-SCR complex, varies between the quiescent center and the cortex endodermis initials, which contributed to the fundamental understanding of the functional role of this complex in stem cell maintenance. The SHR-SCR complex acts to spatially restrict $S H R$ expression to the endodermis, leading to cell-specific control of cell division $(\underline{83}, \underline{143})$. In another example, N\&B was used in the root to show that ARF7 and ARF19 form higher-order protein assemblies (up to 10 -mers) that limit auxin responsiveness $(\underline{118})$. Thus, cross N\&B provides a complementary approach to FRET-FLIM, and using both techniques together provides the most information about protein binding and protein-protein complex stoichiometries within a sample. Second, the dynamics of protein complex composition can be analyzed by imaging over multiple time points during plant development. Third, protein complex information can be built in computational models to more accurately fit them to experimental data and vice versa and can be used to validate model predictions.

Computational models also often integrate kinetic data, which are generally more difficult to experimentally determine, but the difficulty can be addressed with scanning FCS. By using the same raster scan for $\mathrm{N \& B}$ analysis in a process called raster image correlation spectroscopy ${ }^{\text {ix }}$

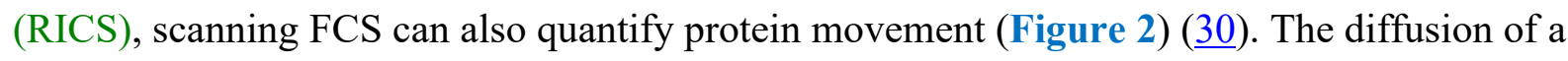
fluorescent protein can be calculated from these time series images by removing the fluctuations of fluorescence that result from the speed of the scan, an intrinsic setting of the confocal microscope ( $\underline{30})$. As such, the diffusion rate of SHR between the vasculature initials, stem cells that express $S H R$, and the neighboring cortex endodermis initial and quiescent center cells was determined (21). As with N\&B, RICS can also correlate two fluorophores in a process called cross-correlation RICS (cross RICS) to measure how the binding between two proteins affects their movement (34). Thus, RICS allows for the measurement of protein movement in different regions of a single cell or in different cell types of a multicellular organism.

One of the drawbacks of RICS is that it cannot detect whether movement is restricted at barriers within cells, such as the nuclear envelope or organelles, or between cells, such as cell membranes and walls. To address this drawback, the pair correlation function $(\mathrm{pCF})^{\mathrm{x}}$ was developed to measure protein movement through a barrier ( $\underline{65})$. pCF uses a single line scanned across the potential diffusion barrier to calculate the probability of fluorescence fluctuations in 
This manuscript has been accepted in Annual Reviews of Plant Biology (ARPB). This version has not undergone final editing. Please refer to the final version at the ARPB.

the case of free movement and then correlates this probability with the measured fluorescence (32). When the pCF analysis shows no autocorrelation at the diffusion barrier, the protein cannot cross the barrier, while autocorrelation suggests that the protein can pass the barrier (Figure 2) (32). Therefore, pCF can reveal whether protein movement within or between cells is restricted

in any manner. Specifically, pCF has been used to unravel the molecular mechanisms underlying stem cell maintenance in the root stem cell niche. The stem cell identity in the root stem cell niche is maintained through the controlled regulation of asymmetric cell divisions by the SHRSCR complex, among others $(\underline{143})$. With pCF analyses, the authors $(\underline{21})$ were able to detect SHR movement from the vasculature initials to the cortex endodermis initials, where it forms a complex with SCR that in turn restricts the diffusion of SHR back to the vasculature. The molecular mechanisms regulating stem cell maintenance were even further unraveled with pCF, revealing that WUSCHEL RELATED HOMEOBOX 5 (WOX5), a central regulator in maintaining the dormant state of the quiescent center, can diffuse to the vasculature initials where it regulates downstream targets such as SHR (20).

\section{USING LIGHT SHEET FLUORESCENCE MICROSCOPY TO UNDERSTAND THE DYNAMICS UNDERLYING PLANT GROWTH}

LSFM is a recent powerful addition to the arsenal of modalities available to study development at the mesoscopic scale (147). LSFM uses two distinct optical axes. The first one illuminates a thin slice of the specimen with a sheet of laser light while keeping the rest of the sample in the dark. The second optical axis is orthogonal to the illumination axis and collects the light emitted by the fluorophores in the illuminated volume of the specimen. By moving the sample stepwise across the sheet and taking an image at each position, a stack of images encapsulating the whole volume of the specimen is collected (Figure 3) $(\underline{69}, \underline{167})$. 
This manuscript has been accepted in Annual Reviews of Plant Biology (ARPB). This version has not undergone final editing. Please refer to the final version at the ARPB.

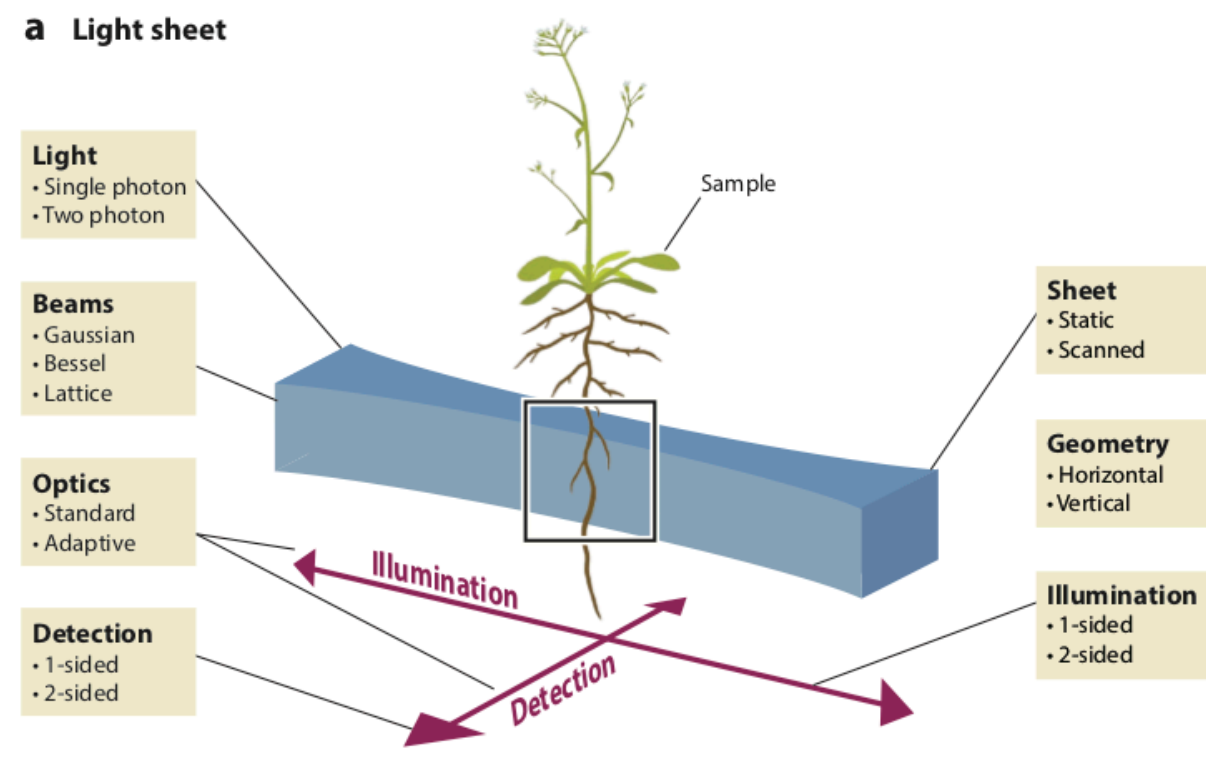

b Root moves through light sheet

C Z-Stack imaging
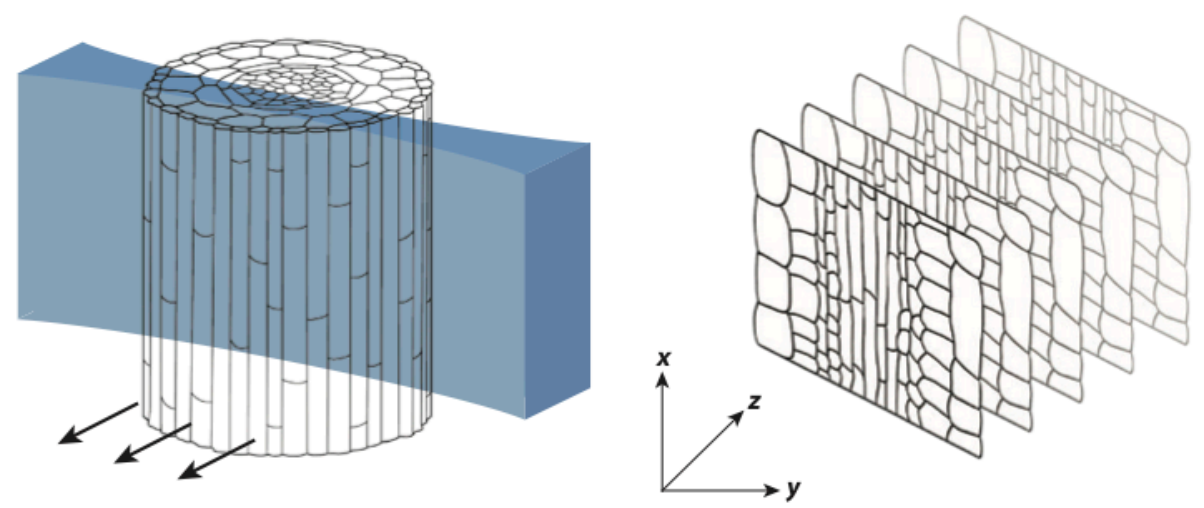

Figure 3 Light sheet imaging of Arabidopsis root. (a) A light sheet microscope consists of two orthogonal optical axes. A thin volume of the vertically positioned Arabidopsis root is illuminated by a sheet of laser light coming from the illumination axis. The light emitted by this selectively illuminated plane is collected by the second optical axis (detection). LSFM designs differ in the type of illumination, the type of beams, the number of sheets and cameras used, their positioning, and the use of adaptive optics. $(b-c)$ By moving the root stepwise into the light sheet, serial optical sections are collected, and they allow reconstruction of volumetric information.

The LSFM design combines the speed and sensitivity of wide-field fluorescence microscopy with the optical sectioning ability of confocal microscopy, making LSFM particularly amenable to imaging of organs and organisms while minimizing photodamage. At any given time, only a small volume of the specimen is illuminated; therefore, during a three-dimensional (3D) scan, 
This manuscript has been accepted in Annual Reviews of Plant Biology (ARPB). This version has not undergone final editing. Please refer to the final version at the ARPB.

the total amount of laser light received by the whole specimen is minimal (one to two times the amount received by a single plane). In a confocal microscope, for each focal plane imaged, the whole specimen is illuminated, and the emitted light coming from regions above and below it is eliminated by the pinhole placed in front of the detector. Consequently, the total amount of light received by the sample during a 3D scan is proportional to the number of planes imaged. In addition, for laser scanning confocal microscopy, the pinhole imposes a point-by-point scanned detection. In LSFM, images are acquired by modern electron-multiplying charge-coupled device or scientific complementary metal-oxide-semiconductor cameras that have higher signal-to-noise ratios than the photomultipliers found in most laser scanning confocal microscopy. This combination of high sensitivity, speed of image acquisition, and parsimonious use of the energy illuminating the sample makes LSFM particularly suited for imaging biological processes over extended periods of time and/or at high frequency. Many variations of the basic LSFM design have been implemented over the years in lab-built and commercial solutions. LSFM designs differ in the type of illumination (single-photon versus two-photon, static versus scanned versus Bessel beams or lattices), the number of sheets and cameras used simultaneously, their positioning (horizontal versus vertical), and the use of adaptive optics. These variations provide specific advantages for each application and specimen but also illustrate that LSFM setups can appear too specialized: Changing magnification is not easily done, and usually only a single specimen can be imaged at a time $(\underline{117}, \underline{122})$. This limitation inspired the development of a multisample holder that allows simultaneous imaging of several specimens (27).

Application of LSFM to plant biology has bloomed in the last seven years. Most LSFM designs (custom built and commercial) use one or two illumination sheets arranged horizontally with the plant positioned vertically in the imaging chamber (ㅁ). Imitation of close to natural conditions during imaging is achieved by the illumination of aerial tissue with a light-emitting diode system mimicking sunlight that can simulate the light patterns of long or short days. In addition, a perfusion system exchanges media in the chamber, ensuring a constant supply of nutrients as well as the removal of contaminants or generated toxic compounds ( $\underline{96})$. This permits imaging over the course of several days with no apparent damage $(\underline{159}, \underline{163})$. Mounting the plant on the LSFM device to ensure stability over time is specific for each application ( $\underline{9}$, $\underline{109}, \underline{159}, \underline{162})$. To date, the majority of LSFM imaging in plants has been on the Arabidopsis roots because of their ideal geometry and good optical properties. Yet, imaging of other organs 
This manuscript has been accepted in Annual Reviews of Plant Biology (ARPB). This version has not undergone final editing. Please refer to the final version at the ARPB.

(leaves, flowers, shoots meristems) and species, including crops (Medicago, rice, tomato), has been achieved (see $\underline{110}$ for a comprehensive review).

A strength of LSFM is its ability to bridge microscopic and mesoscopic scales. LSFM can image fast subcellular processes in the context of intact organs and over the course of several hours or days. LSFM was used in Arabidopsis to relate cellular proliferation with the growth of the primary root $(\underline{27}, \underline{96}, \underline{138})$. LSFM was used to quantify the abundance of the cytoskeletal END BINDING PROTEIN 1C (EB1c), an atypical and plant-specific microtubule plus-endtracking protein in the growing Arabidopsis root (107). It revealed that EB1c, previously only studied in the context of dividing cells, resides in the nucleus between divisions, where its accumulation correlates with the nuclear surface as the cells differentiate. This use of LSFM illustrates how quantitative analysis can uncover new links between the cytoskeleton, nuclear size, and differentiation. LSFM was also used to reveal that the MITOGEN-ACTIVATED PROTEIN KINASE 6 (MPK6) associates with the phragmoplasts where it controls proper division of root cells (142). At subcellular levels, LSFM has been used to observe $\mathrm{Ca}^{2+}$ dynamics where it characterized calcium oscillations associated with growth rate and auxin effects on growth (17). LSFM also enabled the imaging of cytosolic and nuclear $\mathrm{Ca}^{2+}$ waves deep into a growing root, revealing the existence of a long-postulated process of $\mathrm{Ca}^{2+}$ percolation across tissues (25).

LSFM is particularly well suited to investigate the development of plant organs over several days and elucidate, by bridging the cell to the organ scale, how plant organs are shaped. LSFM was used to image Arabidopsis lateral root development, to uncover and quantify the ellipse-toround shape transition of the lateral root primordium ( $\underline{92})$, and to precisely analyze the patterns of cell divisions $(\underline{160})$. These studies uncovered that the typical dome shape aspect of the lateral root primordium and its internal organization in layers are the result of the accommodation of the overlying tissue to the primordium outgrowth and the geometric pattern of cell division, respectively. LSFM uncovered that the swelling of the lateral root founder cells deep in the primary root is an important signal perceived by the endodermis, which signals back to these cells and allows their further development (159). LSFM helped researchers to understand how the growth angle of a lateral root in regard to the gravity vector results from the asymmetric distribution of auxin yielding to the asymmetric expansion of epidermis cells and the bending of the young lateral root (129). 
This manuscript has been accepted in Annual Reviews of Plant Biology (ARPB). This version has not undergone final editing. Please refer to the final version at the ARPB.

\section{MICRODEVICES FOR IMAGING GROWTH AND ORGAN DEVELOPMENT}

Plant growth and development, as well as physiology and metabolism, are sensitive to environmental stress conditions, which means that specimen handling and variable conditions during live imaging may affect the validity and reproducibility of obtained results. Therefore, technical innovations are needed to reduce sample handling while still allowing for chemical and biological treatments. A classic example is the Fåhraeus slide, with roots growing between a microscope slide and a cover glass that are separated by a spacer $(\underline{10}, \underline{40})$. The use of these slides revealed the effect of bacterial nodulation factors on root hair deformation during the onset of symbiosis between rhizobia and legumes $(\underline{42}, \underline{61})$.

Over the past decade, microdevices fabricated from the silicone-based organic polymer polydimethylsiloxane (PDMS) have become increasingly popular tools for the cultivation, perfusion, and imaging of plant cells or organs (Figure 4). Biologically inert and gas permeable, PDMS has been widely used in microfluidic lab-on-a-chip devices ${ }^{\mathrm{xi}}$ that are cast and fixed onto optical glass to create chambers that facilitate microscopic observation of live specimens $(\underline{170})$. Due to their design flexibility, lab-on-a-chip-based microdevices have a wide range of applications for the study of plants with diverse morphologies and their development under different environmental conditions. The first plant microdevices were developed to cultivate primary Arabidopsis roots $(\underline{16}, \underline{56}, \underline{99})$, Camellia or Torenia pollen tubes $(\underline{66}, \underline{132}, \underline{173})$, Arabidopsis ovules (113), or the filamentous protonemal tissue of the moss model Physcomitrella patens (ㅁ) under controlled conditions at the microscope for experiments lasting hours to days or weeks. Recently, this technology has been adapted for roots of larger plants, such as Oryza sativa and Populus tremuloides $(\underline{55}, \underline{68})$. As we will illustrate in the following paragraphs, several discoveries in plant physiology, developmental and cell biology that were recently made using microdevices demonstrate their potential for the unveiling of yet unknown molecular mechanisms in plants. 
This manuscript has been accepted in Annual Reviews of Plant Biology (ARPB). This version has not undergone final editing. Please refer to the final version at the ARPB.

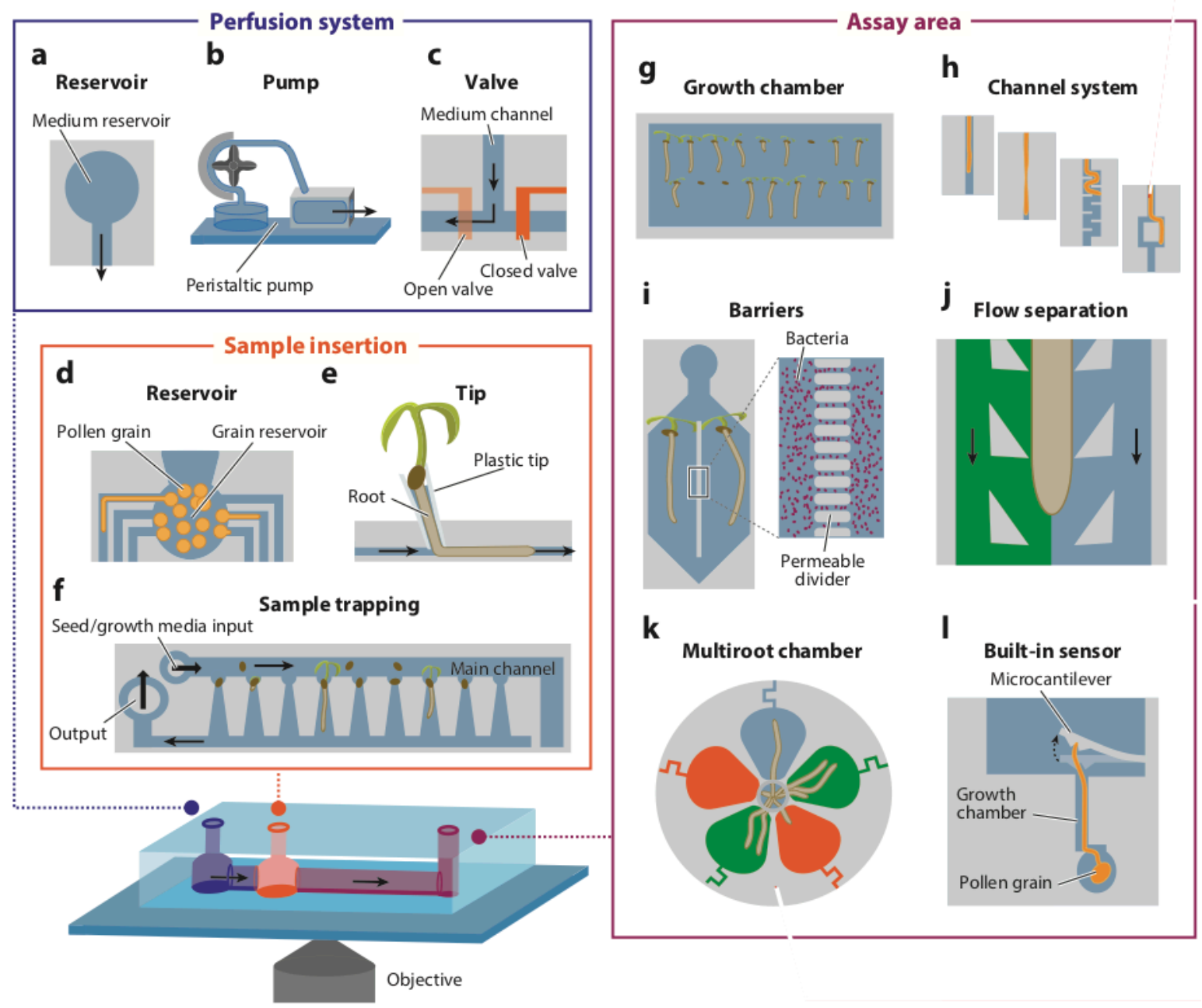

Figure 4 Versatile design of microdevices for plant live imaging. Microdevices can be adapted to various experimental needs. Three main functional elements should be considered: $(a-c)$ the perfusion system, which allows the medium to flow within the device in a passive $(a)$ or active way $(b, c),(d-f)$ the sample insertion, and $(g-l)$ the assay area where the microscopic acquisition occurs. Examples using such concepts include References $(a) \underline{3}, \underline{67}, 111,136,169$, and 170; $(b)$ $\underline{16}, \underline{50}, \underline{54}$, and $128 ;($ c) $\underline{29}, \underline{43}, \underline{55}, \underline{56}, \mathbf{7 5}, \underline{78}, \underline{86}, \underline{122}$, and $154 ;$ (d) 136 and $170 ;(e) 43,54,67$, $\underline{96}, \underline{122}$, and $\underline{169} ;(f) \underline{16}, \underline{50}, \underline{73}, \underline{128}$, and $\underline{130} ;(g) \underline{16} ;(h) \underline{2}, \underline{3}, \underline{29}, \underline{43}, \underline{49}, \underline{54}, \underline{55}, \underline{75}, \underline{78}, \underline{86}, \underline{96}$, $\underline{98}, \underline{111}, \underline{122}, \underline{129}, \underline{136}$, and $\underline{169} ;(i) \underline{96} ;(j) \underline{130}$ and $\underline{143} ;(k) \underline{68}$; and $(l) \underline{50}, \underline{62}$, and $\underline{110}$.

A main advantage of microfluidic imaging platforms over other sample mounting and perfusion systems is the minimal sample handling. Pollen grains, plant protoplasts, blended moss tissue, and even ovules can be manually introduced as suspension directly into a dedicated germination chamber of the device or immobilized into casted traps (Figure 4) $(\underline{113}, \underline{131}, \underline{133}$, 139). Seedling roots grow into the device autonomously, which prevents mechanical damage 
This manuscript has been accepted in Annual Reviews of Plant Biology (ARPB). This version has not undergone final editing. Please refer to the final version at the ARPB.

$(\underline{16}, \underline{56})$. Another significant improvement is the increase in throughput that can be achieved through the parallelization of experiments within such miniaturized platforms. The RootChip was initially developed for the parallel imaging of $8(\underline{56})$ and later 16 roots $(\underline{76})$ at a time, which enabled fluorescent sensor-based measurements of small molecule dynamics in living tissue. The RootArray enabled the analysis of gene expression patterns in up to 64 roots of Arabidopsis in a single chamber $(\underline{16})$. Upon changing growth conditions, such as a drop in $\mathrm{pH}$ from 5.7 to 4.6 or a deficiency in iron or sulfur, the authors observed dramatic but transient changes in gene expression. For example, the homeodomain transcription factor WOX5, typically expressed exclusively in the quiescent center, was transiently detectable within the root elongation zone (16). By leveraging and combining the technical advances made in microfluidic devices and LSFM, researchers developed a 3D-printed device, the Multi-sample Arabidopsis Growth and Imaging Chamber (MAGIC), that is able to image whole organs for a longer period of time (27). MAGIC has been custom-designed for a commercial, dual-sided illumination light sheet microscope, and it allows researchers to grow and image four Arabidopsis roots simultaneously. Moreover, with the design of MAGIC, shoots grow outside of the agar, allowing gas exchange during the imaging process, which leads to successful imaging of cell division in the root meristem over a period of 48 hours (27). Thus, the expression of pCYCB1;1:GFP, a marker for cell division, was tracked for 24 hours under conditions of iron sufficiency, iron deficiency, heat stress, and combined iron deficiency and heat stress (13a). Surprisingly, the change in the number and timing of cell divisions under the combined stress differed from the additive effect of the individual stresses, indicating that combinatorial stresses trigger unique stress responses (13a).

Taking advantage of the trapping of up to 40 Arabidopsis ovules in a microcage array (113) and employing two-photon microscopy enabled the first live imaging of embryogenesis over three days from the first zygote division to a heart-shaped 64-cell embryo (느). Following cell fate specification, this study established a cell lineage tree and revealed cell damage-induced cell fate conversion. Upon laser-ablation of the apical cell of a proembryo within the microcage, the authors revealed a compensatory change in cell identity in a neighboring nonembryonic cell toward an embryonic fate as indicated by cell type-specific transcriptional reporters ( $\underline{54})$.

The applications of microfluidic lab-on-a-chip devices for plant studies go beyond providing a platform for specimen mounting for microscopy; they include chemical, biotic, and mechanical 
This manuscript has been accepted in Annual Reviews of Plant Biology (ARPB). This version has not undergone final editing. Please refer to the final version at the ARPB.

stimulation as well as the probing of mechanical properties of cells and tissues (Figure 4). While a main motivation for the use of perfusion devices is to keep conditions constant, devices such as the RootChip contain micromechanical valves (157) and thereby enable pulsed treatments with a complete exchange of the chamber condition in less than $10 \mathrm{~s}(\underline{56}, \underline{57})$. Several studies took advantage of such on-chip valve systems in combination with genetically encoded fluorescent biosensors to visualize molecular dynamics during membrane transport $(\underline{56}, \underline{87})$, to reveal stimulus-specific calcium signaling in response to biotic or abiotic stress elicitors $(\underline{29}, \underline{79})$, or to uncover the dynamic distribution of the phytohormones abscisic acid (므) and gibberellin ( $\underline{125})$ in growing Arabidopsis roots. While most microscope setups only allow for horizontal specimen mounting, one study employed a vertically mounted RootChip to investigate the inhibitory effect of auxin on root cell elongation, while avoiding interference by gravitropic responses (43). The authors found that, upon auxin treatment, roots responded within $30 \mathrm{~s}$ by slowing down their growth, reaching a 70\% slower growth rate after $10 \mathrm{~min}(\underline{43})$. By comparing the response of mutants lacking auxin signaling components such as the auxin efflux carrier AUX1 or the auxin coreceptors TIR1, AFB2, and AFB3, the authors were able to provide further strong evidence for the existence of an auxin signaling pathway that acts independently of transcriptional regulation (43).

In comparison to larger perfusion systems, the small chamber volumes of microdevices allow for a reduced consumption of applied compounds and a more rapid and uniform treatment of the specimen. However, specialized channel architectures can also enable local or asymmetric stimulation of specific parts of tissues or single cells and thereby facilitate studies on mechanisms of stimulus perception, local and systemic adaptive responses, and chemotaxis. An early pioneering work offered the possibility to apply an auxin treatment perpendicular to the root axis, with the stimulation stream focused by multilaminar flow and thereby locally inducing outgrowth of root hairs (99). To investigate pollen tube chemotaxis toward female gametophytes, two studies examined the response to ovule-derived attractants by offering growing pollen tubes a choice to grow toward an empty chamber or one filled with ovules $(\underline{66}, \underline{173})$. Instead of perpendicular stimulation, asymmetric conditions can also be generated in parallel to the specimen's growth axis. A device for pollen tubes allowed researchers to subject a growing cell to asymmetric growth conditions, revealing that growth direction follows the optimal calcium concentration in the environment $(\underline{133})$. Asymmetric conditions are also highly relevant for 
This manuscript has been accepted in Annual Reviews of Plant Biology (ARPB). This version has not undergone final editing. Please refer to the final version at the ARPB.

studies on root development, as environmental heterogeneity is a hallmark of soil. The dualflow-RootChip device used a micropillar array to guide Arabidopsis root growth in the middle of the observation chamber and took advantage of two laminar streams of the medium separated by the root in the center (146). Experiments involving the asymmetric availability of inorganic phosphate on either side of the root $(2.4 \mathrm{mM}$ versus $0.01 \mathrm{mM})$ resulted in rapid, cell-autonomous stimulation of root hair growth on the inorganic-phosphate-rich side that preceded rather than followed transcriptional regulation (146). Together with the aforementioned transcriptionindependent response to auxin (43), these studies point to yet unknown, fast, nongenomic regulatory mechanisms of cellular growth. The unveiling of these mechanisms will greatly benefit from the ability to perform long-term live-cell imaging in microfluidic perfusion systems.

Another major aim for root biology is to understand biotic interactions with other organisms in the rhizosphere. Lab-on-a-chip-based devices offer solutions to accomplish live imaging of the infection and colonization of roots by symbiotic or pathogenic microbiota (145). However, very few studies have so far explored the potential of plant-microbe or plant-herbivore interactions with lab-on-a-chip-based devices $(\underline{3}, \underline{97}, \underline{112})$. The Tracking Root Interactions System enabled, for example, the study of the preferential association of Bacillus subtilis with the elongation zones of roots of different Arabidopsis genotypes in a double-chamber device housing two parallel roots that were separated by a perforated barrier, allowing for free movement of bacteria (97).

While chemical conditions and biotic interactions mainly influence root growth and development at the metabolic level, mechanical forces exerted by and on the root play a more direct role in root growth rate and direction and, as a consequence, root system architecture ( $\underline{36})$. To explore the intrinsic forces exerted by growing plant cells on their environment, several strategies have been developed in microdevices that take advantage of known physical properties of PDMS. Using the deformation of sidewalls in narrow growth channels as readout, researchers determined a dilating pressure of Camellia pollen tubes of $0.15 \mathrm{mPa}(\underline{132})$. Alternative approaches used to determine growth force in pollen tubes were the application of capacitive force sensors $(\underline{15})$ or microcantilevers at the end of growth channels that became deflected by the tube growing against them ( $\underline{50})$. Furthermore, when growing pollen tubes against cantilevers, the authors observed frequent bursting of the pollen tubes when the cantilevers approached maximum deflection, which indicated that the reduced growth rate caused by the counterforce of 
This manuscript has been accepted in Annual Reviews of Plant Biology (ARPB). This version has not undergone final editing. Please refer to the final version at the ARPB.

the cantilever induced a cellular compensation mechanism that led to a weakening of the apical cell wall ( $\underline{50})$. A cantilever-based approach had also been applied to measure the growth force of A. thaliana, Nicotiana benthamiana, and Capsella rubella roots in a microdevice, which yielded species-specific values $(\underline{63}, \underline{111})$.

Beyond the intrinsic forces exerted by plant cells during growth, extrinsic forces play a significant role in modulating growth behavior. To understand how extrinsic mechanical forces are perceived by pollen tubes, investigators have developed microdevices such as TipChip that include obstacles and wavy channel architectures for pollen tubes $(\underline{2}, \underline{49})$. Using devices with specialized compression valves that crossed the observation channels and allowed for actuated mechanical stimulation of pollen tubes enabled the quantification of mechanical properties of tipgrowing cells and the demonstration of the interplay between turgor pressure and cell wall stiffness during tip growth (그). In another study, pollen tubes and root hairs were forced to grow through gaps with a width of less than one-tenth of the cell's normal diameter (172), revealing a surprising capability of tip-growing cells to overcome such obstacles without stalling growth or bursting.

Though powerful, lab-on-a-chip-based devices do not reach the level of structural complexity attained by soil on roots. Synthetic, particle-rich substrates like transparent soil, consisting of irregularly shaped polymer particles with the same refractive index as water, have been shown to produce similar root system architectures as soil or sand (프). Since the material is virtually invisible, it represents a promising way for root phenotyping at microscopic detail, taking soil structure and other environmental cues into account (108). Great potential for new discoveries lies in the vast possibilities to create synthetic environments that combine multiple iterations of the above-mentioned features and thereby to model ecosystems and unveil trade-off and decision-making mechanisms during the growth of plant cells and the development of plant organs $(\underline{141}, \underline{145})$.

\section{NONDESTRUCTIVE IMAGING METHODS TO QUANTIFY BELOW- AND ABOVEGROUND MACROSCOPIC PLANT TRAITS}

Accurate phenotyping of agronomic traits is critical for increased crop production and the development of new plant varieties. While the affordability and efficiency of genotyping are increasing, the cost and efficiency of phenotyping remain bottlenecks. Manual phenotyping at 
This manuscript has been accepted in Annual Reviews of Plant Biology (ARPB). This version has not undergone final editing. Please refer to the final version at the ARPB.

high spatial and temporal resolution is impractical and time-consuming (46), motivating the development of automated, imaging-based phenotyping approaches aimed at quantifying roots and shoots.

Phenotyping methods for root systems can be divided into two broad classes: noninvasive and destructive. While destructive methods are still the primary means for capturing images of field-grown root systems, noninvasive methods for plants grown in solid substrates have become increasingly available for greenhouse and growth-chamber-grown plants. The improved phenotyping capabilities afforded by noninvasive methods are necessary to accurately quantify dynamic root traits for crop improvement. There is no single ideal solution for macroscopic root imaging, and the choice of platform depends on the biological question, experimental parameters, and laboratory resource constraints. In addition, each imaging approach requires significant image postprocessing and analysis, with specific software being developed for many methods.

2D noninvasive root phenotyping methods include growth on agar plates (101) or in gellan gum ( $\underline{72})$, germination paper (rhizoslides) (8) or pouches $(\underline{154})$, or nylon fabric in hydroponics (rhizoponics) (요). In these methods, roots are generally imaged with either a flatbed scanner or a digital camera. The major advantages of these approaches are that they provide root growth data at low cost, are accessible to most laboratories, and are relatively high throughput. Some (e.g., growth in gellan gum) can also be converted into 3D information $(\underline{23}, \underline{153})$. Using this approach, 89 quantitative trait loci for $252 \mathrm{D}$ and 3D root traits were identified in a rice recombinant inbred line population grown in gellan gum, which provide breeding targets for specific root architecture traits (153). A drawback of these methods is that the use of artificial media can impact the root architecture, and thus extrapolation to plants grown in soil is challenging. 2D methods that use soil or soil-like substrates include the clear pot method (123), which images roots that grow at the periphery of soil-filled containers; growth in rhizoboxes such as Glo-Roots (121), where plants expressing luciferase reporters are grown in soil between polycarbonate plastic plates and imaged in a luminescence imaging system; and transparent soil methods $(\underline{35}, \underline{93})$.

One of the biggest challenges in root phenotyping is the nondestructive 3D imaging of soilgrown roots. Recent advances in tomographic methods make them a promising choice for nondestructive imaging in three dimensions. In tomographic imaging methods, an object- 
This manuscript has been accepted in Annual Reviews of Plant Biology (ARPB). This version has not undergone final editing. Please refer to the final version at the ARPB.

penetrating wave or beam creates $2 \mathrm{D}$ image cross sections that are stitched together to generate 3D images. MRI, X-ray $\mu \mathrm{CT}$, and PET are three of the more common tomographic methods used for noninvasive 3D root phenotyping in soil (Figure $5 b$ ). The major advantage of these methods is their ability to view root system architecture or function nondestructively in native environments.

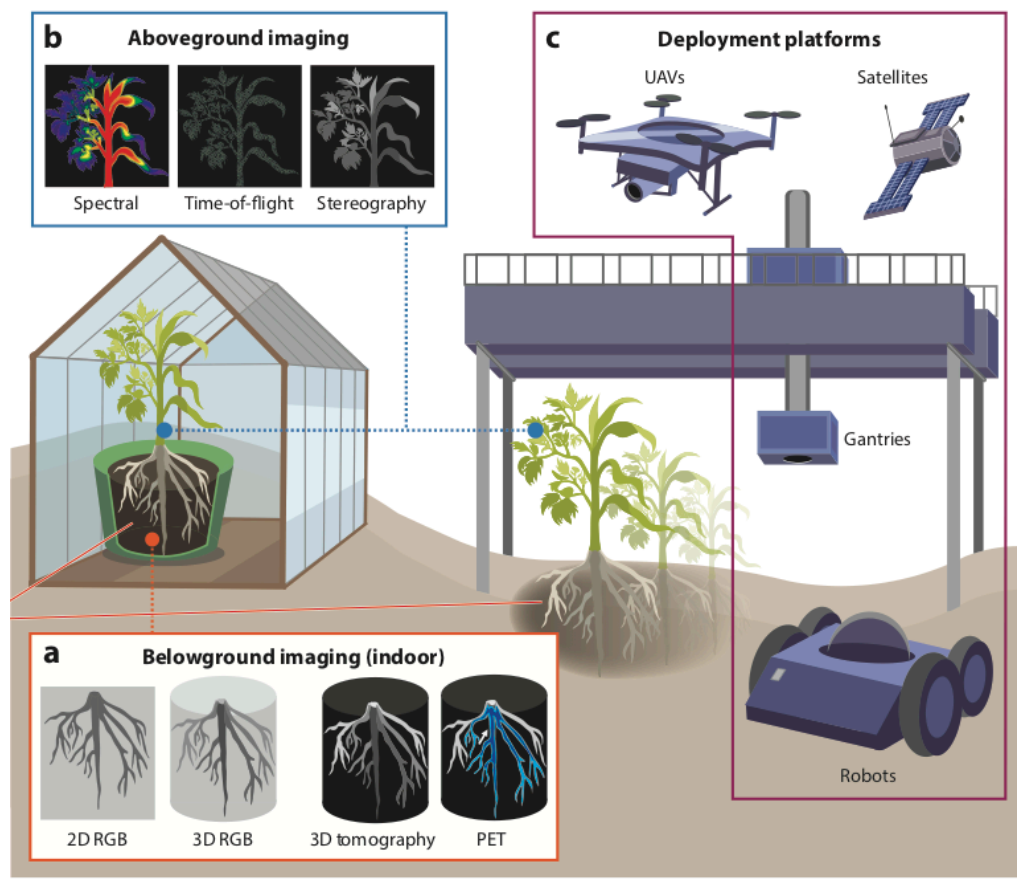

Figure 5 Imaging of whole plants and organs in monocots or dicots (shown as a schematic hybrid here) can take place in a greenhouse (left) or field (right). (a) Belowground imaging approaches are primarily limited to greenhouse use. These include, from left to right, 2D RGB images from soil-like substrates, 3D representations reconstructed from these 2D images, 3D tomography imaging such as MRI or X-ray $\mu \mathrm{CT}$, and imaging of nutrient transport such as PET. Field-based belowground imaging is not pictured here but is discussed in the text. (b) Aboveground imaging approaches for the greenhouse or field are equivalent. These include, from left to right, heat maps produced from spectral imaging, 3D point clouds produced from time-of-flight imaging, and stereographic 3D imaging. (c) For field-based imaging there are multiple automated deployment platforms that can be utilized, depending on the project goals. Aerial deployment platforms include UAVs (drones; top left) and satellites (top right), whereas ground-based deployment platforms include overhead gantry systems (middle) and ground mobile robots (bottom). Together, these technologies are being used to provide whole plant and organ images for plant improvement. Abbreviations: RGB, red green blue; MRI, magnetic resonance imaging; PET, positron emission tomography; X-ray $\mu \mathrm{CT}$, X-ray microcomputed tomography; UAV, unmanned aerial vehicle. 
This manuscript has been accepted in Annual Reviews of Plant Biology (ARPB). This version has not undergone final editing. Please refer to the final version at the ARPB.

MRI uses nuclear magnetic resonance to detect signals from atomic nuclei, usually ${ }^{1} \mathrm{H}$ (protons) in plants. Magnetic fields are used to manipulate the nuclear magnetic moment or rotational spin of protons. Ultimately this information is processed into 3D image data sets. MRI has been used to examine root-nematode interactions (4) $)$, storage roots (100), and cereal root development (158), but it can also be used to view the distribution of root water uptake (148) and mobility $(\underline{128}, \underline{134}, \underline{171})$. MRI is sensitive to the soil substrate, and distinguishing nuclear magnetic resonance signals originating from the water in soil versus the water in roots can be difficult. These challenges can be overcome by adjusting the experimental and acquisition parameters on the MRI to increase root-to-soil contrast (127). Although MRI imaging time is long and thus not suitable for large populations, under the right experimental conditions the contrast between root and soil is sufficiently robust so that image processing is relatively straightforward (158).

In recent years, $\mathrm{X}$-ray $\mu \mathrm{CT}$ has moved to the forefront for noninvasive 3D imaging in soil. As X-rays pass through a sample, a portion of the X-rays are absorbed, and X-ray intensity decreases. This decrease in intensity is known as attenuation and is a function of the density of the sample (94). One major challenge in X-ray $\mu \mathrm{CT}$ is that the attenuation values of roots and soil overlap, which creates significant challenges for data analysis (155), and attenuation values may vary in different zones of the root. There is also a trade-off between sample size and image resolution, but recent improvements in X-ray $\mu \mathrm{CT}$ scanners and image processing algorithms have significantly improved the methodology $(\underline{103})$. X-ray $\mu \mathrm{CT}$ has been used to examine the impact of soil and substrate density on root growth and architecture $(\underline{14}, \underline{126})$, root-root interactions $(\underline{95})$, potato tuber growth $(\underline{114})$, and root-fungal interaction (150). This technology also enhanced our understanding of lateral root development in soil. Using X-ray $\mu \mathrm{CT}$, OrmanLigeza et al. (108a) found that maize and barley roots suppress lateral root formation when roots grow through air spaces in soil and are not in contact with water. This observation led to additional experiments that showed that transient abscisic acid application suppressed lateral root formation by altering lateral root prebranch sites near the root tip.

There appear to be minimal deleterious effects of X-ray $\mu \mathrm{CT}$ at low total dosages $(<30 \mathrm{~Gy})$ on root growth in most plants or on microbial population biomass (11a, $\underline{44}, \underline{175})$, but dosage effects on plant growth vary by plant species (reviewed in 175). Another type of X-ray CT, synchrotron X-ray computed tomography, uses high-intensity X-rays from a synchrotron to 
This manuscript has been accepted in Annual Reviews of Plant Biology (ARPB). This version has not undergone final editing. Please refer to the final version at the ARPB.

noninvasively view roots. This method offers micrometer-level resolution and is useful for noninvasively viewing root cellular anatomy. Synchrotron X-ray computed tomography has been used to assess root hydraulics at the cellular level (26) and root hair-soil interactions (마) $)$.

Unlike MRI and X-ray $\mu \mathrm{CT}$, PET is used not for observing root structures, but for investigating their function. PET quantifies the distribution of a positron-emitting radioisotope (such as ${ }^{11} \mathrm{C}$ or ${ }^{13} \mathrm{~N}$ ) in a plant over time with spatial resolution of approximately $1-5 \mathrm{~mm}$. This allows observation of the kinetics of nutrient uptake, transport, and movement throughout the plant in three dimensions. Plant PET scanners $(\underline{7}, \underline{73}, \underline{166})$ have been used to examine photoassimilate transport and allocation in sorghum (77) and the impact of root herbivory on auxin biosynthesis and flux in maize roots (119). By measuring the time of arrival of carbon-11labeled IAA in two different regions of maize roots, auxin transport speed was shown to decrease in maize roots after Western corn rootworm attack (119). PET has also been used in conjunction with MRI or X-ray $\mu \mathrm{CT}$ for structure-function studies $(\underline{48}, \underline{73})$. While PET is a very good tool for addressing questions regarding root function, it is limited by high cost, low accessibility, and low throughput.

For many researchers, nondestructive root imaging in the field is the ultimate goal, but methods for this have yet to be fully realized. Current methods include rhizotrons and minirhizotrons and ground-penetrating radar. Rhizotrons are similar to underground walk-in chambers with windows that look at the soil (102), while minirhizotrons are transparent tubes that can be inserted into the soil at various places and angles throughout a field. Rhizotrons and minirhizotrons allow successive measurements of the same roots over time and are well-suited to investigate questions about fine roots $(\underline{18}, \underline{38}, \underline{75}, \underline{165})$ and nodules. Minirhizotron imaging was used to identify the effects of high carbon dioxide concentration $\left(\mathrm{CO}_{2}\right)$ and reduced precipitation on nodule distribution and number on field-grown soybean roots. This work demonstrated the complex, interactive effects of high $\mathrm{CO}_{2}$ and reduced precipitation, which caused an increase in nodules per length of root and volume of soil. Surprisingly, given the increase in nodules, soybean leaves grown in high $\mathrm{CO}_{2}$ and reduced precipitation did not have increased nitrogen on a leaf-mass basis. This may have been because the increased nodules were distributed on roots found in shallow, drier soil, which may have reduced the $\mathrm{N}_{2}$-fixing activity of each nodule. One drawback of rhizotrons and minirhizotrons is that they capture only a small portion of the root system and do not provide a 3D view. In contrast, ground-penetrating radar uses high-frequency 
This manuscript has been accepted in Annual Reviews of Plant Biology (ARPB). This version has not undergone final editing. Please refer to the final version at the ARPB.

radio waves to obtain images of belowground structures. Ground-penetrating radar is high cost and low resolution and has limited use in crop systems. To date, it has been used to image large tree roots $(\underline{5}, \underline{149})$, cassava tubers $(\underline{28})$, winter wheat, and energy cane $(\underline{90})$.

While many of the tomography approaches used for belowground imaging have also been used for aboveground imaging, the size of the instruments has limited these analyses to lab- or greenhouse-based experiments. In contrast to belowground imaging, the goal of nondestructive approaches in the field has proven more attainable for aboveground traits. Various field-based phenotyping platforms have partially automated the process of collecting field data, providing a means for rapid phenotyping to identify target plant traits (169). The challenge for aboveground field-based plant imaging has been the choice of imaging approach and the method of deploying that imaging platform in the field.

As with root imaging, there is no single ideal solution for aboveground macroscopic imaging, and the approach depends on the biological question, experimental parameters, and laboratory resource constraints. The simplest approach to aboveground phenotyping is the acquisition of $2 \mathrm{D}$ images obtained from the visible light spectrum [red, green, blue (RGB) cameras] and nearinfrared light spectrum (Figure 5) (역). These methods are reliable for detecting discoloration and thermal properties of individual plants $(\underline{89})$ and can be used to extract measures of plant

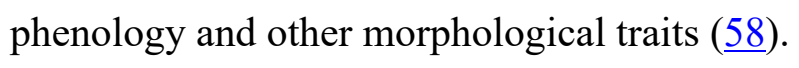

Other 2D imaging approaches take advantage of the spectral properties of plant tissues via imaging spectroscopy (e.g., multispectral and hyperspectral ${ }^{\text {xii }}$ ). Imaging spectroscopy combines digital imaging and spectroscopy to provide spatial maps of reflectance for a given wavelength of light, often visualized as a heatmap. Multispectral cameras acquire data from discrete and defined wide bandwidths (usually 5 to 12 bands), whereas hyperspectral cameras are capable of capturing thousands of narrow 5-20-nm spectral bands (1). Hyperspectral cameras provide higher resolution spectral data than multispectral cameras, but they are significantly more expensive, and much of the additional wavelength data has yet to be related to specific plant traits. In both systems, maintaining the appropriate calibration is critical for data quality and consistency of spectral measurements (오). Imaging spectroscopy has enabled the quantification of agronomically relevant plant traits $(\underline{169})$. For example, the normalized difference vegetation index, which quantifies the amount of green vegetation $(\underline{156})$, and photochemical reflectance index, which quantifies the photosynthetic efficiency of plants $(\underline{47})$, were established to relate 
This manuscript has been accepted in Annual Reviews of Plant Biology (ARPB). This version has not undergone final editing. Please refer to the final version at the ARPB. multispectral values to agronomic traits.

Approaches for the 3D reconstruction and quantification of aerial tissues include ranging sensors, time-of-flight (ToF) cameras ${ }^{x i i i}$, and stereography ${ }^{x i v}$ (Figure 5). These imaging approaches, often representing data in the form of point clouds, are gaining popularity for their ability to directly measure plant geometry via remote sensing. Ranging sensors typically emit either sound or light and measure the time for an accompanying detector to receive a reflection, which makes direct observations of plant geometry possible without physical contact. Two examples of ranging sensors include ultrasonic and LiDAR. Ultrasonic sensors are susceptible to diffusion even over short distances, so they are mainly used for overall plant height measurements (1ㅡ), whereas LiDAR can resolve submillimeter geometries at high temporal resolution (151). Ranging approaches can generate dense 3D reconstructions of an entire field. However, the data sets are often sizable and require significant postprocessing, and moderately priced LiDAR devices can cost between $\$ 10,000$ and $\$ 20,000$. In contrast, ToF cameras use reflected light in a similar way as ranging sensors and cost significantly less but have much lower resolution. Light emitted for ToF sensing is typically in the infrared spectrum, which is directly affected by incident light, making these sensors noisy and unreliable, especially in areas with high levels of sunlight penetration. Despite the drawbacks, ToF has been shown to be a practical method for field-based data collection ( $\underline{82})$. Finally, stereo cameras, which are in the same price range as ToF cameras, bridge the gap between visual and 3D imaging. Stereo cameras are composed of two cameras separated by a known distance, which allows the triangulation of object distance based on the perceived image shift between the two cameras $(\underline{81})$. Stereo cameras are useful because they are robust in well-lit areas and have significantly higher resolution when compared to ToF cameras; however, they suffer from image correspondence errors between the two cameras. Overall, ToF cameras have been shown to have favorable results over stereo vision despite their sensitivity to ambient light (78). ToF sensors are quite promising and in intensive development for increasing the throughput of data acquisition for plant breeding.

Imaging sensors can be mounted on different data collection platforms depending on the plant trait and resolution required. Options for deploying imaging sensors to capture stalk and leaf phenotypes at high resolution include ground mobile robots $(\underline{104}, \underline{174})$ and existing field equipment. For example, imaging sensors have been mounted on irrigation systems to reduce 
This manuscript has been accepted in Annual Reviews of Plant Biology (ARPB). This version has not undergone final editing. Please refer to the final version at the ARPB.

cost and provide high-resolution overhead imaging (⒐5). Unmanned aerial vehicles can also be outfitted with (generally small/lightweight) sensors as an alternative, low-cost method for imaging from overhead but are subject to flight restrictions and are power and payload constrained (176). Satellite imaging is another technique for measuring RGB and near-infrared light that is cost effective for imaging large areas, although the results have relatively low temporal and spatial resolution (105). The choice of data collection platform depends primarily on the target phenotype and resolution.

Advances in macroscopic plant imaging techniques have been significant; however, major knowledge gaps have to be filled before we are able to bridge the gap between genotype and phenotype. Challenges in root phenotyping include nondestructively imaging root systems in the field. Challenges in shoot phenotyping include the advancement of dynamic deployment platforms. For both types of phenotyping, image analysis and trait data extraction (although not discussed here) remain bottlenecks. Ultimately, tying these traits back to plant function and crop improvement remains at the forefront of motivation for macroscopic plant imaging.

\section{CONCLUSION}

Above we describe different imaging modalities used to collect both microscopic and macroscopic data on plant cells, tissues, organs, and populations. Images from a microscopic level can provide information about the mode of action of proteins, cell-to-cell communication, and dynamical cellular processes. Mesoscopic imaging informs us about the dynamics of cell behavior in tissues and organs in their environment. On a macroscopic level, images can yield morphometric phenotypic data, such as leaf size and root architecture, but also intrinsic plant traits such as chlorophyll content. The collection of images obtained across these different scales generates large data sets for which meta-analysis is the key next step. To enable meta-analysis, we need to further develop centralized databases to store imaging data and query tools to extract data from these images to optimally take advantage of available imaging resources. Future work should focus on employing computational methods such as machine learning, deep learning, and neural networks, which can extract and integrate large quantities of information from these collections of images. Additionally, other large-scale sources of data such as cell-type specific and/or organism-wide transcriptomics and proteomics should be integrated with these imaging 
This manuscript has been accepted in Annual Reviews of Plant Biology (ARPB). This version has not undergone final editing. Please refer to the final version at the ARPB.

data to allow scientists to connect morphological phenotypes with molecular phenotypes. As our biological models continue to grow and integrate processes from different temporal and spatial scales, the sustained development and refinement of these multiscale imaging methods are necessary.

\section{SUMMARY POINTS}

1. The dynamics and localization of protein interactions can be visualized with Förster resonance energy transfer coupled with fluorescence lifetime imaging (FRET-FLIM).

2. Recent advances in scanning fluorescent correlation spectrometry in the plant kingdom allow for the quantification of protein movement and the qualification of protein oligomerization and complex stoichiometry.

3. LSFM enables the low-phototoxicity imaging of cells in tissues and organs over extended periods of time by combining the sensitivity of wide-field microscopy and the specificity of confocal microscopy to image fluorescence across an entire organ.

4. A wide range of designs for microfluid devices allow for long-term imaging in controlled environmental conditions that may be adapted to research interest.

5. Nuclear magnetic resonance imaging (MRI), X-ray microcomputed tomography (X-ray $\mu \mathrm{CT}$ ), and positron emission tomography (PET) have been used to image root-system architecture and function nondestructively in the field.

6. Nondestructive imaging of shoots of single plants or whole populations is achieved through red, green, blue (RGB) cameras, multispectral and hyperspectral cameras, timeof-flight (ToF) cameras, ultrasonic and light detection and ranging (LiDAR) sensors, or a combination of these techniques.

\section{DISCLOSURE STATEMENT}

The authors are not aware of any affiliations, memberships, funding, or financial holdings that might be perceived as affecting the objectivity of this review.

\section{AUTHOR CONTRIBUTIONS}

I.B., N.M.C., L.V.d.B., and R.S. contributed to the writing of the section titled FRET-FLIM and 
This manuscript has been accepted in Annual Reviews of Plant Biology (ARPB). This version has not undergone final editing. Please refer to the final version at the ARPB.

Scanning FCS as Tools to Determine Protein Dynamics at Cellular Resolution, of which I.B. wrote the FRET-FLIM paragraphs and N.M.C., L.V.d.B., and R.S. wrote the scanning FCS paragraphs. A.M. contributed to the writing of the section titled Using Light Sheet Microscopy to Understand the Dynamics Underlying Plant Growth. M.G. and G.G. contributed to the writing of the section titled Micro-Devices for Imaging Growth and Organ Development. A.S., H.G.T., A.S.I.P., and E.E.S. contributed to the writing of the section titled Nondestructive Imaging Methods to Quantify Below- and Above-Ground Macroscopic Plant Traits. All authors contributed to the writing of the introduction and conclusions and the design of the figures.

\section{ACKNOWLEDGMENTS}

We thank Lindsay Erndwein of Illustrations by LindZeaMays for illustrating the figures of this article. Research in the Sozzani lab was provided by the National Science Foundation (NSF) (CAREER MCB-1453130), NSF/Biotechnology and Biological Sciences Research Council (BBSRC) (NSF MCB 1517058), and the North Carolina Agricultural \& Life Sciences Research Foundation in the College of Agriculture and Life Sciences at North Carolina State University (to R.S.). Research in the Maizel lab is supported by DFG FOR2581, the Land BadenWürttemberg, the Chica und Heinz Schaller Stiftung, the CellNetworks cluster of excellence, and the Boehringer Ingelheim Foundation. E.E.S. is supported by grants from the Delaware Biosciences Center for Advanced Technology, the University of Delaware Research Foundation, and the Thomas Jefferson Fund. A.S. is supported by a University of Delaware Graduate Student Fellowship. Research in the A.S.I.P. lab is supported by grants from the Foundation for Food and Agriculture Research (FFAR), the NSF, Purdue University start-up funds, and USDA Hatch Funds (IND011293). G.G. is supported by research group funds from the Excellence Cluster CellNetworks and a grant from the Deutsche Forschungsgemeinschaft (GR 4559/3-1). I.B. was supported by King Abdullah University of Science and Technology (KAUST). 
This manuscript has been accepted in Annual Reviews of Plant Biology (ARPB). This version has not undergone final editing. Please refer to the final version at the ARPB.

\section{LITERATURE CITED}

1. Adão T, Hruška J, Pádua L, Bessa J, Peres E, et al. 2017. Hyperspectral imaging: a review on UAV-based sensors, data processing and applications for agriculture and forestry. Remote Sens. 9(11): 1110

2. Agudelo CG, Sanati Nezhad A, Ghanbari M, Naghavi M, Packirisamy M, Geitmann A. 2013. TipChip: a modular, MEMS-based platform for experimentation and phenotyping of tipgrowing cells. Plant J. 73(6):1057-68

3. Aufrecht JA, Timm CM, Bible A, Morrell-Falvey JL, Pelletier DA, et al. 2018. Quantifying the spatiotemporal dynamics of plant root colonization by beneficial bacteria in a microfluidic habitat. Adv. Biosyst. 2(6):1800048

4. Bacia K, Schwille P. 2003. A dynamic view of cellular processes by in vivo fluorescence autoand cross-correlation spectroscopy. Methods 29(1):74-85

5. Barton CVM, Montagu KD. 2004. Detection of tree roots and determination of root diameters by ground penetrating radar under optimal conditions. Tree Physiol. 24(12):1323-31

6. Bascom CS, Wu S-Z, Nelson K, Oakey J, Bezanilla M. 2016. Long-term growth of moss in microfluidic devices enables subcellular studies in development. Plant Physiol. 172(1):28-37

7. Beer S, Streun M, Hombach T, Buehler J, Jahnke S, et al. 2010. Design and initial performance of PlanTIS: a high-resolution positron emission tomograph for plants. Phys. Med. Biol. 55(3):635-46

8. Berson T, von Wangenheim D, Takáč T, Šamajová O, Rosero A, et al. 2014. Trans-Golgi network localized small GTPase RabA1d is involved in cell plate formation and oscillatory root hair growth. BMC Plant Biol. 14(1):252

9. Berthet B, Maizel A. 2016. Light sheet microscopy and live imaging of plants. J. Microsc. 263(2):158-64

10. Bhuvaneswari TV, Solheim B. 1985. Root hair deformation in the white clover/Rhizobium trifolii symbiosis. Physiol. Plant. 63(1):25-34

11. Bindels DS, Haarbosch L, van Weeren L, Postma M, Wiese KE, et al. 2016. mScarlet: a 
This manuscript has been accepted in Annual Reviews of Plant Biology (ARPB). This version has not undergone final editing. Please refer to the final version at the ARPB.

bright monomeric red fluorescent protein for cellular imaging. Nat. Methods 14:53-56

11a. Blaser SRGA, Schlüter S, Vetterlein D. 2018. How much is too much?-Influence of X-ray dose on root growth of faba bean (Vicia faba) and barley (Hordeum vulgare). PLOS ONE 13(3):e0193669

12. Boer DR, Freire-Rios A, van den Berg WAM, Saaki T, Manfield IW, et al. 2014. Structural basis for DNA binding specificity by the auxin-dependent ARF transcription factors. Cell 156(3):577-89

13. Bücherl CA, van Esse GW, Kruis A, Luchtenberg J, Westphal AH, et al. 2013. Visualization of BRI1 and BAK1(SERK3) membrane receptor heterooligomers during brassinosteroid signaling. Plant Physiol. 162(4):1911-25

13a. Buckner E, Madison I, Chou H, Matthiadis A, Melvin CE, et al. 2019. Automated imaging, tracking, and analytics pipeline for differentiating environmental effects on root meristematic cell division. Front. Plant Sci. 10:148714. Burr-Hersey JE, Mooney SJ, Glyn Bengough A, Mairhofer S, Ritz K. 2017. Developmental morphology of cover crop species exhibit contrasting behaviour to changes in soil bulk density, revealed by X-ray computed tomography. PLOS ONE 12(7):e0181872

15. Burri JT, Vogler H, Läubli NF, Hu C, Grossniklaus U, Nelson BJ. 2018. Feeling the force: how pollen tubes deal with obstacles. New Phytol. 220(1):187-95

16. Busch W, Moore BT, Martsberger B, Mace DL, Twigg RW, et al. 2012. A microfluidic device and computational platform for high-throughput live imaging of gene expression. Nat. Methods 9(11):1101-6

17. Candeo A, Doccula FG, Valentini G, Bassi A, Costa A. 2017. Light sheet fluorescence microscopy quantifies calcium oscillations in root hairs of Arabidopsis thaliana. Plant Cell Physiol. 58(7):1161-72

18. Chairungsee N, Gay F, Thaler P, Kasemsap P, Thanisawanyangkura S, et al. 2013. Impact of tapping and soil water status on fine root dynamics in a rubber tree plantation in Thailand. Front. Plant Sci. 4:538 
This manuscript has been accepted in Annual Reviews of Plant Biology (ARPB). This version has not undergone final editing. Please refer to the final version at the ARPB.

19. Chang C-W, Mycek M-A. 2012. Quantitative molecular imaging in living cells via FLIM. In Reviews in Fluorescence 2010, ed. C Geddes, pp. 173-98. New York: Springer

20. Clark NM, Buckner E, Fisher AP, Nelson EC, Nguyen TT, et al. 2019. Stem-cell-ubiquitous genes spatiotemporally coordinate division through regulation of stem-cell-specific gene networks. bioRxiv 517250. https://doi.org/10.1101/517250

21. Clark NM, Hinde E, Winter CM, Fisher AP, Crosti G, et al. 2016. Tracking transcription factor mobility and interaction in Arabidopsis roots with fluorescence correlation spectroscopy. eLife 5:e14770

22. Clark NM, Sozzani R. 2017. Measuring protein movement, oligomerization state, and protein-protein interaction in Arabidopsis roots using scanning fluorescence correlation spectroscopy (scanning FCS). -In Plant Genomics: Methods and Protocols, ed. W Busch, pp. 251-66. New York: Humana Press

23. Clark RT, MacCurdy RB, Jung JK, Shaff JE, McCouch SR, et al. 2011. Three-dimensional root phenotyping with a novel imaging and software platform. Plant Physiol. 156(2):455-65

24. Clegg RM. 2009. Förster resonance energy transfer-FRET what is it, why do it, and how it's done. In FRET and Film Techniques, ed. TWJ Gadella, pp. 1-57. Amsterdam: Elsevier

25. Costa A, Candeo A, Fieramonti L, Valentini G, Bassi A. 2013. Calcium dynamics in root cells of Arabidopsis thaliana visualized with selective plane illumination microscopy. PLOS ONE 8(10): 75646

26. Cuneo IF, Knipfer T, Brodersen CR, McElrone AJ. 2016. Mechanical failure of fine root cortical cells initiates plant hydraulic decline during drought. Plant Physiol. 172(3):1669-78

27. de Luis Balaguer MA, Ramos-Pezzotti M, Rahhal MB, Melvin CE, Johannes E, et al. 2016. Multi-sample Arabidopsis Growth and Imaging Chamber (MAGIC) for long term imaging in the ZEISS Lightsheet Z.1. Dev. Biol. 419(1):19-25

28. Delgado A, Hays DB, Bruton RK, Ceballos H, Novo A, et al. 2017. Ground penetrating radar: a case study for estimating root bulking rate in cassava (Manihot esculenta Crantz). Plant Methods 13:65 
This manuscript has been accepted in Annual Reviews of Plant Biology (ARPB). This version has not undergone final editing. Please refer to the final version at the ARPB.

29. Denninger P, Bleckmann A, Lausser A, Vogler F, Ott T, et al. 2014. Male-female communication triggers calcium signatures during fertilization in Arabidopsis. Nat. Commun. $5(1): 4645$

30. Digman MA, Brown CM, Sengupta P, Wiseman PW, Horwitz AR, Gratton E. 2005. Measuring fast dynamics in solutions and cells with a laser scanning microscope. Biophys $J$. 89(2):1317-27

31. Digman MA, Dalal R, Horwitz AF, Gratton E. 2008. Mapping the number of molecules and brightness in the laser scanning microscope. Biophys J. 94(6):2320-32

32. Digman MA, Gratton E. 2011. Lessons in fluctuation correlation spectroscopy. Annu. Rev. Phys. Chem. 62:645-68

33. Digman MA, Gratton E. 2012. Scanning image correlation spectroscopy. Bioessays 34(5):377-85

34. Digman MA, Wiseman PW, Horwitz AR, Gratton E. 2009. Detecting protein complexes in living cells from laser scanning confocal image sequences by the cross correlation raster image spectroscopy method. Biophys. J. 96(2):707-16

35. Downie H, Holden N, Otten W, Spiers AJ, Valentine TA, Dupuy LX. 2012. Transparent soil for imaging the rhizosphere. PLOS ONE 7(9):e44276

36. Dupuy L, Mimault M, Patko D, Ladmiral V, Ameduri B, et al. 2018. Micromechanics of root development in soil. Curr. Opin. Genet. Dev. 51:18-25

37. Elson EL. 2011. Fluorescence correlation spectroscopy: past, present, future. Biophys. J. 101(12):2855-70

38. Espeleta JF, West JB, Donovan LA. 2009. Tree species fine-root demography parallels habitat specialization across a sandhill soil resource gradient. Ecology 90(7):1773-87

39. Fahlgren N, Gehan MA, Baxter I. 2015. Lights, camera, action: High-throughput plant phenotyping is ready for a close-up. Curr. Opin. Plant Biol. 24:93-99

40. Fåhraeus G. 1957. The infection of clover root hairs by nodule bacteria studied by a simple 
This manuscript has been accepted in Annual Reviews of Plant Biology (ARPB). This version has not undergone final editing. Please refer to the final version at the ARPB.

glass slide technique. Microbiology 16(2):374-81

41. Farooque AA, Chang YK, Zaman QU, Groulx D, Schumann AW, Esau TJ. 2013. Performance evaluation of multiple ground based sensors mounted on a commercial wild blueberry harvester to sense plant height, fruit yield and topographic features in real-time. Comput. Electron. Agric. 91:135-44

42. Faucher C, Maillet F, Vasse J, Rosenberg C, van Brussel AAN, et al. 1988. Rhizobium meliloti host range nodH gene determines production of an alfalfa-specific extracellular signal. J. Bacteriol. 170(12):5489-99

43. Fendrych M, Akhmanova M, Merrin J, Glanc M, Hagihara S, et al. 2018. Rapid and reversible root growth inhibition by TIR1 auxin signalling. Nat. Plants 4(7):453-59

44. Flavel RJ, Guppy CN, Tighe M, Watt M, McNeill A, Young IM. 2012. Non-destructive quantification of cereal roots in soil using high-resolution X-ray tomography. J. Exp. Bot. 63(7):2503-11

45. Förster T. 1946. Energiewanderung und fluoreszenz. Naturwissenschaften 33(6):166-75

46. Furbank RT, Tester M. 2011. Phenomics - technologies to relieve the phenotyping bottleneck. Trends Plant Sci. 16(12):635-44

47. Gamon JA, Peñuelas J, Field CB. 1992. A narrow-waveband spectral index that tracks diurnal changes in photosynthetic efficiency. Remote Sens. Environ. 41(1):35-44

48. Garbout A, Munkholm LJ, Hansen SB, Petersen BM, Munk OL, Pajor R. 2012. The use of $\mathrm{PET} / \mathrm{CT}$ scanning technique for 3D visualization and quantification of real-time soil/plant interactions. Plant Soil 352(1-2):113-27

49. Ghanbari M, Nezhad AS, Agudelo CG, Packirisamy M, Geitmann A. 2014. Microfluidic positioning of pollen grains in lab-on-a-chip for single cell analysis. J. Biosci. Bioeng. 117(4):504-11

50. Ghanbari M, Packirisamy M, Geitmann A. 2018. Measuring the growth force of invasive plant cells using Flexure integrated Lab-on-a-Chip (FiLoC). Technology 6(3):101-9 
This manuscript has been accepted in Annual Reviews of Plant Biology (ARPB). This version has not undergone final editing. Please refer to the final version at the ARPB.

51. Goedhart J, van Weeren L, Hink MA, Vischer NOE, Jalink K, Gadella TWJ Jr. 2010. Bright cyan fluorescent protein variants identified by fluorescence lifetime screening. Nat. Methods 7(2):137

52. Goedhart J, Von Stetten D, Noirclerc-Savoye M, Lelimousin M, Joosen L, et al. 2012. Structure-guided evolution of cyan fluorescent proteins towards a quantum yield of $93 \%$. Nat. Commun. 3:751

53. Goergen CJ, Sosnovik DE. 2011. From molecules to myofibers: multiscale imaging of the myocardium. J. Cardiovasc. Transl. Res. 4(4):493-503

54. Gooh K, Ueda M, Aruga K, Park J, Arata H, et al. 2015. Live-cell imaging and optical manipulation of Arabidopsis early embryogenesis. Dev. Cell 34(2):242-51

55. Gros M-FS, Shinde SV, Akins C, Johnson JL, Zerbs S, et al. 2018. RMI-chip: a microfluidics setup for functional imaging of microbial interactions with tree roots. bioRxiv 506774. https://doi.org/10.1101/506774

56. Grossmann G, Guo W-J, Ehrhardt DW, Frommer WB, Sit RV, et al. 2011. The RootChip: an integrated microfluidic chip for plant science. Plant Cell 23(12):4234-40

57. Grossmann G, Meier M, Cartwright HN, Sosso D, Quake SR, et al. 2012. Time-lapse fluorescence imaging of Arabidopsis root growth with rapid manipulation of the root environment using the RootChip. J. Vis. Exp. 65:e4290

58. Guo W, Fukatsu T, Ninomiya S. 2015. Automated characterization of flowering dynamics in rice using field-acquired time-series RGB images. Plant Methods 11:7

59. Haberland JA. 2001. AgIIS, Agricultural Irrigation Imaging System, design and application. PhD Thesis, Univ. Ariz., Tucson, AZ

60. Harter K, Meixner AJ, Schleifenbaum F. 2012. Spectro-microscopy of living plant cells. Mol. Plant 5(1):14-26

61. Heidstra R, Geurts R, Franssen H, Spaink HP, van Kammen A, Bisseling T. 1994. Root hair deformation activity of nodulation factors and their fate on Vicia sativa. Plant Physiol. 105(3):787-97 
This manuscript has been accepted in Annual Reviews of Plant Biology (ARPB). This version has not undergone final editing. Please refer to the final version at the ARPB.

62. Heinze KG, Jahnz M, Schwille P. 2004. Triple-color coincidence analysis: one step further in following higher order molecular complex formation. Biophys. J. 86(1):506-16

63. Hida H, Ozoe K, Kanno I, Higashiyama T, Notaguchi M. 2014. On-chip force measurement system for investigating plant-root growth. Paper presented at 2014 International Symposium on Micro-NanoMechatronics and Human Science (MHS), Nagoya, Japan, Nov. 10-12

64. Hillnhütter C, Sikora RA, Oerke E-C, van Dusschoten D. 2012. Nuclear magnetic resonance: a tool for imaging belowground damage caused by Heterodera schachtii and Rhizoctonia solani on sugar beet. J. Exp. Bot. 63(1):319-27

65. Hinde E, Cardarelli F, Digman MA, Kershner A, Kimble J, Gratton E. 2011. The impact of mitotic versus interphase chromatin architecture on the molecular flow of EGFP by pair correlation analysis. Biophys. J. 100(7):1829-36

66. Horade M, Kanaoka MM, Kuzuya M, Higashiyama T, Kaji N. 2013. A microfluidic device for quantitative analysis of chemoattraction in plants. RSC Adv. 3(44):22301-7

67. Hu C, Munglani G, Vogler H, Ndinyanka Fabrice T, Shamsudhin N, et al. 2017. Characterization of size-dependent mechanical properties of tip-growing cells using a lab-onchip device. Lab Chip 17(1):82-90

68. Chai HH, Chen F, Zhang SJ, Li YD, Lu ZS, et al. 2019. Multi-chamber petaloid root-growth chip for the non-destructive study of the development and physiology of the fibrous root system of Oryza sativa. Lab Chip 19:2383-93

69. Huisken J, Swoger J, Del Bene F, Wittbrodt J, Stelzer EHK. 2004. Optical sectioning deep inside live embryos by selective plane illumination microscopy. Science 305(5686):1007-9

70. Immink RGH, Gadella TWJ Jr., Ferrario S, Busscher M, Angenent GC. 2002. Analysis of MADS box protein-protein interactions in living plant cells. PNAS 99(4):2416-21

71. Immink RGH, Tonaco IAN, de Folter S, Shchennikova A, van Dijk ADJ, et al. 2009. SEPALLATA3: the 'glue' for MADS box transcription factor complex formation. Genome Biol. 10(2):R24

72. Iyer-Pascuzzi AS, Symonova O, Mileyko Y, Hao Y, Belcher H, et al. 2010. Imaging and 
This manuscript has been accepted in Annual Reviews of Plant Biology (ARPB). This version has not undergone final editing. Please refer to the final version at the ARPB.

analysis platform for automatic phenotyping and trait ranking of plant root systems. Plant Physiol. 152(3):1148-57

73. Jahnke S, Menzel MI, Van Dusschoten D, Roeb GW, Bühler J, et al. 2009. Combined MRIPET dissects dynamic changes in plant structures and functions. Plant J. 59(4):634-44

74. Jiang H, Xu Z, Aluru MR, Dong L. 2014. Plant chip for high-throughput phenotyping of Arabidopsis. Lab Chip 14(7):1281-93

75. Johnson MG, Tingey DT, Phillips DL, Storm MJ. 2001. Advancing fine root research with minirhizotrons. Environ. Exp. Bot. 45(3):263-89

76. Jones AM, Danielson JÅH, ManojKumar SN, Lanquar V, Grossmann G, Frommer WB. 2014. Abscisic acid dynamics in roots detected with genetically encoded FRET sensors. eLife 3:e 01741

77. Karve AA, Alexoff D, Kim D, Schueller MJ, Ferrieri RA, Babst BA. 2015. In vivo quantitative imaging of photoassimilate transport dynamics and allocation in large plants using a commercial positron emission tomography (PET) scanner. BMC Plant Biol. 15(1):273

78. Kazmi W, Foix S, Alenyà G, Andersen HJ. 2014. Indoor and outdoor depth imaging of leaves with time-of-flight and stereo vision sensors: analysis and comparison. ISPRS J. Photogramm. Remote Sens. 88:128-46

79. Keinath NF, Waadt R, Brugman R, Schroeder JI, Grossmann G, et al. 2015. Live cell imaging with R-GECO1 sheds light on flg22- and chitin-induced transient $\left[\mathrm{Ca}^{2+}\right]_{\text {cyt }}$ patterns in Arabidopsis. Mol. Plant 8(8):1188-200

80. Keyes SD, Zygalakis KC, Roose T. 2017. An explicit structural model of root hair and soil interactions parameterised by synchrotron X-ray computed tomography. Bull. Math. Biol. 79(12):2785-813

81. Kise M, Zhang Q, Rovira Más F. 2005. A stereovision-based crop row detection method for tractor-automated guidance. Biosyst. Eng. 90(4):357-67

82. Klose R, Penlington J, Ruckelshausen A. 2009. Usability study of 3D Time-of-Flight 
This manuscript has been accepted in Annual Reviews of Plant Biology (ARPB). This version has not undergone final editing. Please refer to the final version at the ARPB.

cameras for automatic plant phenotyping. Bornimer Agrartech. Ber. 69:93-105

83. Koizumi K, Hayashi T, Gallagher KL. 2012. SCARECROW reinforces SHORT-ROOT signaling and inhibits periclinal cell divisions in the ground tissue by maintaining SHR at high levels in the endodermis. Plant Signal. Behav. 7(12):1573-77

84. Komis G, Mistrik M, Šamajová O, Ovečka M, Bartek J, Šamaj J. 2015. Superresolution live imaging of plant cells using structured illumination microscopy. Nat. Protoc. 10(8):1248-63

85. Komis G, Novák D, Ovečka M, Šamajová O, Šamaj J. 2018. Advances in imaging plant cell dynamics. Plant Physiol. 176(1):80-93

86. Kriechbaumer V, Botchway SW, Slade SE, Knox K, Frigerio L, et al. 2015. Reticulomics: Protein-protein interaction studies with two plasmodesmata-localized reticulon family proteins identify binding partners enriched at plasmodesmata, endoplasmic reticulum, and the plasma membrane. Plant Physiol. 169(3):1933-45

87. Lanquar V, Grossmann G, Vinkenborg JL, Merkx M, Thomine S, Frommer WB. 2014. Dynamic imaging of cytosolic zinc in Arabidopsis roots combining FRET sensors and RootChip technology. New Phytol. 202(1):198-208

88. Le Marié C, Kirchgessner N, Flütsch P, Pfeifer J, Walter A, Hund A. 2016. RADIX: rhizoslide platform allowing high throughput digital image analysis of root system expansion. Plant Methods 12(1):40

89. Li L, Zhang Q, Huang D. 2014. A review of imaging techniques for plant phenotyping. Sensors 14(11):20078-111

90. Liu X, Dong X, Xue Q, Leskovar DI, Jifon J, et al. 2018. Ground penetrating radar (GPR) detects fine roots of agricultural crops in the field. Plant Soil 423:517-31

91. Long Y, Stahl Y, Weidtkamp-Peters S, Postma M, Zhou W, et al. 2017. In vivo FRET-FLIM reveals cell-type-specific protein interactions in Arabidopsis roots. Nature 548:97-102

92. Lucas M, Kenobi K, von Wangenheim D, Voß U, Swarup K, et al. 2013. Lateral root morphogenesis is dependent on the mechanical properties of the overlaying tissues. PNAS 110(13):5229-34 
This manuscript has been accepted in Annual Reviews of Plant Biology (ARPB). This version has not undergone final editing. Please refer to the final version at the ARPB.

93. Ma L, Shi Y, Siemianowski O, Yuan B, Egner TK, et al. 2019. Hydrogel-based transparent soils for root phenotyping in vivo. PNAS 116(22):11063-68

94. Mahesh M. 2002. Search for isotropic resolution in CT from conventional through multiplerow detector. Radiographics 22(4):949-62

95. Mairhofer S, Sturrock CJ, Bennett MJ, Mooney SJ, Pridmore TP. 2015. Extracting multiple interacting root systems using X-ray microcomputed tomography. Plant J. 84(5):1034-43

96. Maizel A, von Wangenheim D, Federici F, Haseloff J, Stelzer EHK. 2011. High-resolution live imaging of plant growth in near physiological bright conditions using light sheet fluorescence microscopy. Plant J. 68(2):377-85

97. Massalha H, Korenblum E, Malitsky S, Shapiro OH, Aharoni A. 2017. Live imaging of rootbacteria interactions in a microfluidics setup. PNAS 114(17):4549-54

98. Mathieu L, Lobet G, Tocquin P, Périlleux C. 2015. "Rhizoponics”: a novel hydroponic rhizotron for root system analyses on mature Arabidopsis thaliana plants. Plant Methods 11:3

99. Meier M, Lucchetta EM, Ismagilov RF. 2010. Chemical stimulation of the Arabidopsis thaliana root using multi-laminar flow on a microfluidic chip. Lab Chip 10(16):2147-53

100. Metzner R, van Dusschoten D, Bühler J, Schurr U, Jahnke S. 2014. Belowground plant development measured with magnetic resonance imaging (MRI): exploiting the potential for non-invasive trait quantification using sugar beet as a proxy. Front. Plant Sci. 5:469

101. Miller ND, Parks BM, Spalding EP. 2007. Computer-vision analysis of seedling responses to light and gravity. Plant J. 52(2):374-81

102. Mohamed A, Monnier Y, Mao Z, Lobet G, Maeght J-L, et al. 2017. An evaluation of inexpensive methods for root image acquisition when using rhizotrons. Plant Methods 13:11

103. Mooney SJ, Pridmore TP, Helliwell J, Bennett MJ. 2012. Developing X-ray Computed Tomography to non-invasively image 3-D root systems architecture in soil. Plant Soil 352(1):1-22 
This manuscript has been accepted in Annual Reviews of Plant Biology (ARPB). This version has not undergone final editing. Please refer to the final version at the ARPB.

104. Mueller-Sim T, Jenkins M, Abel J, Kantor G. 2017. The Robotanist: aground-based agricultural robot for high-throughput crop phenotyping. Paper presented at 2017 IEEE International Conference on Robotics and Automation (ICRA), Singapore, May 29-June 3

105. Mulla DJ. 2013. Twenty five years of remote sensing in precision agriculture: key advances and remaining knowledge gaps. Biosyst. Eng. 114(4):358-71

106. Nagy P, Claus J, Jovin TM, Arndt-Jovin DJ. 2010. Distribution of resting and ligand-bound ErbB1 and ErbB2 receptor tyrosine kinases in living cells using number and brightness analysis. PNAS 107(38):16524-29

107. Novák D, Kuchařová A, Ovečka M, Komis G, Šamaj J. 2016. Developmental nuclear localization and quantification of GFP-tagged EB1c in Arabidopsis root using light-sheet microscopy. Front. Plant Sci. 6:1187

108. O’Callaghan FE, Braga RA, Neilson R, MacFarlane SA, Dupuy LX. 2018. New live screening of plant-nematode interactions in the rhizosphere. Sci. Rep. 8(1):1440

108a. Orman-Ligeza B, Morris EC, Parizot B, Lavigne T, Babé A, et al. 2018. The xerobranching response represses lateral root formation when roots are not in contact with water. Curr. Biol. 28(19):3165-73

109. Ovečka M, Vaškebová L, Komis G, Luptovčiak I, Smertenko A, Šamaj J. 2015. Preparation of plants for developmental and cellular imaging by light-sheet microscopy. Nat. Protoc. 10(8):1234-47

110. Ovečka M, von Wangenheim D, Tomančák P, Šamajová O, Komis G, Šamaj J. 2018. Multiscale imaging of plant development by light-sheet fluorescence microscopy. Nat. Plants 4(9):639-50

111. Ozoe K, Hida H, Kanno I, Higashiyama T, Notaguchi M. 2015. Early characterization method of plant root adaptability to soil environments. Paper presented at 2015 28th IEEE International Conference on Micro Electro Mechanical Systems (MEMS), Estoril, Portugal, Jan. $18-22$

112. Parashar A, Pandey S. 2011. Plant-in-chip: microfluidic system for studying root growth 
This manuscript has been accepted in Annual Reviews of Plant Biology (ARPB). This version has not undergone final editing. Please refer to the final version at the ARPB.

and pathogenic interactions in Arabidopsis. Appl. Phys. Lett. 98(26):263703

113. Park J, Kurihara D, Higashiyama T, Arata H. 2014. Fabrication of microcage arrays to fix plant ovules for long-term live imaging and observation. Sens. Actuators B Chem. 191:17885

114. Pérez-Torres E, Kirchgessner N, Pfeifer J, Walter A. 2015. Assessing potato tuber diel growth by means of X-ray computed tomography. Plant Cell Environ. 38(11):2318-26

115. Petrásek Z, Schwille P. 2008. Precise measurement of diffusion coefficients using scanning fluorescence correlation spectroscopy. Biophys. J. 94(4):1437-48

116. Pinkert T, Furkert D, Korte T, Herrmann A, Arenz C. 2017. Amplification of a FRET probe by lipid-water partition for the detection of acid sphingomyelinase in live cells. Angew.

Chem. Int. Ed. 56(10):2790-94

117. Power RM, Huisken J. 2017. A guide to light-sheet fluorescence microscopy for multiscale imaging. Nat. Methods 14(4):360-73

118. Powers SK, Holehouse AS, Korasick DA, Schreiber KM, Clark N, et al. 2019. Nucleocytoplasmic partitioning of ARF proteins controls auxin responses in Arabidopsis thaliana. Mol. Cell 76(1):177-90.e5

119. Qu W, Robert CAM, Erb M, Hibbard BE, Paven M, et al. 2016. Dynamic precision phenotyping reveals mechanism of crop tolerance to root herbivory. Plant Physiol. 172(2):776-88

120. Rademacher EH, Lokerse AS, Schlereth A, Llavata-Peris CI, Bayer M, et al. 2012. Different auxin response machineries control distinct cell fates in the early plant embryo. Dev. Cell 22(1):211-22

121. Rellán-Álvarez R, Lobet G, Lindner H, Pradier P-L, Sebastian J, et al. 2015. GLO-Roots: an imaging platform enabling multidimensional characterization of soil-grown root systems. eLife 4:e07597

122. Reynaud EG, Peychl J, Huisken J, Tomancak P. 2015. Guide to light-sheet microscopy for adventurous biologists. Nat. Methods 12(1):30-34 
This manuscript has been accepted in Annual Reviews of Plant Biology (ARPB). This version has not undergone final editing. Please refer to the final version at the ARPB.

123. Richard CA, Hickey LT, Fletcher S, Jennings R, Chenu K, Christopher JT. 2015. Highthroughput phenotyping of seminal root traits in wheat. Plant Methods 11:13

124. Ries J, Schwille P. 2012. Fluorescence correlation spectroscopy. Bioessays 34(5):361-68

125. Rizza A, Walia A, Lanquar V, Frommer WB, Jones AM. 2017. In vivo gibberellin gradients visualized in rapidly elongating tissues. Nat. Plants 3(10):803-13

126. Rogers ED, Monaenkova D, Mijar M, Nori A, Goldman DI, Benfey PN. 2016. X-ray computed tomography reveals the response of root system architecture to soil texture. Plant Physiol. 171(3):2028-40

127. Rogers HH, Bottomley PA. 1987. In situ nuclear magnetic resonance imaging of roots: influence of soil type, ferromagnetic particle content, and soil water. Agron. J. 79(6):957-65

128. Rokitta M, Peuke AD, Zimmermann U, Haase A. 1999. Dynamic studies of phloem and xylem flow in fully differentiated plants by fast nuclear-magnetic-resonance microimaging. Protoplasma 209(1-2):126-31

129. Rosquete MR, von Wangenheim D, Marhavý P, Barbez E, Stelzer EHK, et al. 2013. An auxin transport mechanism restricts positive orthogravitropism in lateral roots. Curr. Biol. 23(9):817-22

130. Rousseau D, Chéné Y, Belin E, Semaan G, Trigui G, et al. 2015. Multiscale imaging of plants: current approaches and challenges. Plant Methods 11:6

131. Sakai K, Charlot F, Le Saux T, Bonhomme S, Nogué F, et al. 2019. Design of a comprehensive microfluidic and microscopic toolbox for the ultra-wide spatio-temporal study of plant protoplasts development and physiology. bioRxiv 526889. https://doi.org/10.1101/526889 [**AU: This article is published in Plant Methods 15:79 now. Do you want to cite the Plant Methods version?**]

132. Sanati Nezhad A, Naghavi M, Packirisamy M, Bhat R, Geitmann A. 2013. Quantification of cellular penetrative forces using lab-on-a-chip technology and finite element modeling. PNAS 110(20):8093-98

133. Sanati Nezhad A, Packirisamy M, Geitmann A. 2014. Dynamic, high precision targeting of 
This manuscript has been accepted in Annual Reviews of Plant Biology (ARPB). This version has not undergone final editing. Please refer to the final version at the ARPB.

growth modulating agents is able to trigger pollen tube growth reorientation. Plant $J$. 80(1):185-95

134. Scheenen TW, van Dusschoten D, de Jager PA, Van As H. 2000. Quantification of water transport in plants with NMR imaging. J. Exp. Bot. 51(351):1751-59

135. Deleted in proof 136. Schubert V. 2017. Super-resolution microscopy-applications in plant cell research. Front. Plant Sci. 8:531

137. Schwille P, Meyer-Almes FJ, Rigler R. 1997. Dual-color fluorescence cross-correlation spectroscopy for multicomponent diffusional analysis in solution. Biophys. J. 72(4):1878-86

138. Sena G, Frentz Z, Birnbaum KD, Leibler S. 2011. Quantitation of cellular dynamics in growing Arabidopsis roots with light sheet microscopy. PLOS ONE 6(6):e21303

139. Shamsudhin N, Laeubli N, Atakan HB, Vogler H, Hu C, et al. 2016. Massively parallelized pollen tube guidance and mechanical measurements on a lab-on-a-chip platform. PLOS ONE 11(12):e0168138

140. Shaner NC, Lin MZ, McKeown MR, Steinbach PA, Hazelwood KL, et al. 2008. Improving the photostability of bright monomeric orange and red fluorescent proteins. Nat. Methods 5(6):545-51

141. Siemianowski O, Lind KR, Tian X, Cain M, Xu S, et al. 2018. From petri dishes to model ecosystems. Trends Plant Sci. 23(5):378-81

142. Smékalová V, Luptovčiak I, Komis G, Šamajová O, Ovečka M, et al. 2014. Involvement of YODA and mitogen activated protein kinase 6 in Arabidopsis post-embryogenic root development through auxin up-regulation and cell division plane orientation. New Phytol. 203(4):1175-93

143. Sozzani R, Cui H, Moreno-Risueno MA, Busch W, Van Norman JM, et al. 2010. Spatiotemporal regulation of cell-cycle genes by SHORTROOT links patterning and growth. Nature 466(7302):128-32

144. Stahl Y, Grabowski S, Bleckmann A, Kühnemuth R, Weidtkamp-Peters S, et al. 2013. Moderation of Arabidopsis root stemness by CLAVATA1 and ARABIDOPSIS CRINKLY4 
This manuscript has been accepted in Annual Reviews of Plant Biology (ARPB). This version has not undergone final editing. Please refer to the final version at the ARPB.

receptor kinase complexes. Curr. Biol. 23(5):362-71

145. Stanley CE, Grossmann G, Casadevall i Solvas X, deMello AJ. 2016. Soil-on-a-Chip: microfluidic platforms for environmental organismal studies. Lab Chip 16(2):228-41

146. Stanley CE, Shrivastava J, Brugman R, Heinzelmann E, van Swaay D, Grossmann G. 2018. Dual-flow-RootChip reveals local adaptations of roots towards environmental asymmetry at the physiological and genetic levels. New Phytol. 217(3):1357-69

147. Stelzer EHK. 2015. Light-sheet fluorescence microscopy for quantitative biology. Nat. Methods 12(1):23-26

148. Stingaciu L, Schulz H, Pohlmeier A, Behnke S, Zilken H, et al. 2013. In situ root system architecture extraction from magnetic resonance imaging for water uptake modeling. Vadose Zo. J. 12:vzj2012.0019

149. Stover DB, Day FP, Butnor JR, Drake BG. 2007. Effect of elevated $\mathrm{CO}_{2}$ on coarse-root biomass in Florida scrub detected by ground-penetrating radar. Ecology 88(5):1328-34

150. Sturrock CJ, Woodhall J, Brown M, Walker C, Mooney SJ, Ray RV. 2015. Effects of damping-off caused by Rhizoctonia solani anastomosis group 2-1 on roots of wheat and oil seed rape quantified using X-ray Computed Tomography and real-time PCR. Front. Plant Sci. 6:461

151. Thapa S, Zhu F, Walia H, Yu H, Ge Y. 2018. A novel LiDAR-based instrument for highthroughput, 3D measurement of morphological traits in maize and sorghum. Sensors 18(4): 1187

152. Tonaco IAN, Borst JW, de Vries SC, Angenent GC, Immink RGH. 2005. In vivo imaging of MADS-box transcription factor interactions. J. Exp. Bot. 57(1):33-42

153. Topp CN, Iyer-Pascuzzi AS, Anderson JT, Lee C-R, Zurek PR, et al. 2013. 3D phenotyping and quantitative trait locus mapping identify core regions of the rice genome controlling root architecture. PNAS 110(18):E1695-704

154. Trachsel S, Messmer R, Stamp P, Hund A. 2009. Mapping of QTLs for lateral and axile root growth of tropical maize. Theor. Appl. Genet. 119(8):1413-24 
This manuscript has been accepted in Annual Reviews of Plant Biology (ARPB). This version has not undergone final editing. Please refer to the final version at the ARPB.

155. Tracy SR, Roberts JA, Black CR, McNeill A, Davidson R, Mooney SJ. 2010. The X-factor: visualizing undisturbed root architecture in soils using X-ray computed tomography. J. Exp. Bot. 61(2):311-13

156. Tucker CJ. 1979. Red and photographic infrared linear combinations for monitoring vegetation. Remote Sens. Environ. 8(2):127-50

157. Unger MA. 2000. Monolithic microfabricated valves and pumps by multilayer soft lithography. Science 288(5463):113-16

158. van Dusschoten D, Metzner R, Kochs J, Postma JA, Pflugfelder D, et al. 2016. Quantitative $3 \mathrm{D}$ analysis of plant roots growing in soil using magnetic resonance imaging. Plant Physiol. 170(3):1176-88

159. Vermeer JEM, von Wangenheim D, Barberon M, Lee Y, Stelzer EHK, et al. 2014. A spatial accommodation by neighboring cells is required for organ initiation in Arabidopsis. Science 343(6167):178-83

160. von Wangenheim D, Fangerau J, Schmitz A, Smith RS, Leitte H, et al. 2016. Rules and self-organizing properties of post-embryonic plant organ cell division patterns. Curr. Biol. 26(4):439-49

161. von Wangenheim D, Hauschild R, Fendrych M, Barone V, Benková E, Friml J. 2017. Live tracking of moving samples in confocal microscopy for vertically grown roots. eLife 6:e26792

162. von Wangenheim D, Hauschild R, Friml J. 2017. Light sheet fluorescence microscopy of plant roots growing on the surface of a gel. J. Vis. Exp. 119:e55044

163. von Wangenheim D, Rosero A, Komis G, Šamajová O, Ovečka M, et al. 2016. Endosomal interactions during root hair growth. Front. Plant Sci. 6:1262

164. Voss TC, Demarco IA, Day RN. 2005. Quantitative imaging of protein interactions in the cell nucleus. Biotechniques 38(3):413-24

165. Wang P, Shu M, Mou P, Weiner J. 2018. Fine root responses to temporal nutrient heterogeneity and competition in seedlings of two tree species with different rooting 
This manuscript has been accepted in Annual Reviews of Plant Biology (ARPB). This version has not undergone final editing. Please refer to the final version at the ARPB.

strategies. Ecol. Evol. 8(6):3367-75

166. Wang Q, Mathews AJ, Li K, Wen J, Komarov S, et al. 2014. A dedicated high-resolution PET imager for plant sciences. Phys. Med. Biol. 59(19):5613-29

167. Weber M, Huisken J. 2011. Light sheet microscopy for real-time developmental biology. Curr. Opin. Genet. Dev. 21(5):566-72

168. Weissleder R, Pittet MJ. 2008. Imaging in the era of molecular oncology. Nature 452(7187):580-89

169. White JW, Andrade-Sanchez P, Gore MA, Bronson KF, Coffelt TA, et al. 2012. Field-based phenomics for plant genetics research. Field Crop Res. 133:101-12

170. Whitesides GM. 2006. The origins and the future of microfluidics. Nature 442(7101):36873

171. Windt CW, Gerkema E, Van As H. 2009. Most water in the tomato truss is imported through the xylem, not the phloem: a nuclear magnetic resonance flow imaging study. Plant Physiol. 151(2):830-42

172. Yanagisawa N, Sugimoto N, Arata H, Higashiyama T, Sato Y. 2017. Capability of tipgrowing plant cells to penetrate into extremely narrow gaps. Sci. Rep. 7:1403

173. Yetisen AK, Jiang L, Cooper JR, Qin Y, Palanivelu R, Zohar Y. 2011. A microsystembased assay for studying pollen tube guidance in plant reproduction. J. Micromech. Microeng. 21(5):54018

174. Young SN, Kayacan E, Peschel JM. 2018. Design and field evaluation of a ground robot for high-throughput phenotyping of energy sorghum. Precis. Agric. 20(4):697-22

175. Zappala S, Helliwell JR, Tracy SR, Mairhofer S, Sturrock CJ, et al. 2013. Effects of X-ray dose on rhizosphere studies using x-ray computed tomography. PLOS ONE 8(6):e67250

176. Zhang C, Kovacs JM. 2012. The application of small unmanned aerial systems for precision agriculture: a review. Precis. Agric. 13(6):693-712 
This manuscript has been accepted in Annual Reviews of Plant Biology (ARPB). This version has not undergone final editing. Please refer to the final version at the ARPB.

\section{RELATED RESOURCES}

Multi-sample Arabidopsis Growth and Imaging Chamber (MAGIC) for the ZEISS light sheet Z.1 microscope: https:/www.youtube.com/watch?v=spcUzefr35U; shows the preparation of Arabidopsis samples for long-term imaging in the MAGIC

The Root Array: https://www.youtube.com/watch?v=Q9H3F94xHPg; describes a microfluidics device, developed by the Benfey Lab at Duke University, in which plants can be grown and their roots imaged by confocal microscopy over time and without manual intervention; this device, the Root Array, allows for high-throughput, high-resolution data acquisition, making it an important tool for analyzing dynamic gene expression in a living organ

Plant Image Analysis: https://www.plant-image-analysis.org. Maintained by Dr. Guillaume Lobet, provides an excellent resource for image analysis software

i Förster resonance energy transfer with fluorescence lifetime imaging (FRET-FLIM): an imaging method used to detect protein-protein interactions

ii Magnetic resonance imaging (MRI): a noninvasive imaging technique that produces detailed scans of an object of interest using a strong magnetic field and radio waves

iii Tomography: a method for representing a cross section through a solid object using X-rays or ultrasound

iv Scanning fluorescence correlation spectroscopy (scanning FCS): a field of imaging methods used to measure protein movement, oligomeric state, and protein-protein complex stoichiometry

v Light sheet fluorescence microscopy (LSFM): a mesoscopic fluorescence imaging technique relying on separating illumination and detection onto two optical axes

vi Light detection and ranging (LiDAR): an active remote sensing technique, commonly used to measure vegetation height and density, that illuminates a target with laser light and measures the reflected light energy in order to measure distance to the target

vii Number and brightness (N\&B): one of the methods in scanning FCS that is used to determine the oligomeric state of a protein

viii Cross-correlation number and brightness (cross N\&B): one of the methods in scanning FCS that is used to determine the stoichiometry of protein-protein complexes

ix Raster image correlation spectroscopy (RICS): one of the methods in scanning FCS that is used to quantify the diffusion coefficient of a protein

$x$ Pair correlation function (pCF): one of the methods in scanning FCS that is used to determine whether a protein can move through a barrier such as a cell wall or membrane

${ }^{x i}$ Lab-on-a-chip device: microfluidic system that can include various miniaturized features such as valve-channel structures, reservoirs, or chambers for specimen cultivation and observation

xii Hyperspectral spectroscopy: a spectral imaging technique that uses the entire electromagnetic spectrum to collect data and can use data from hundreds to thousands of bands 
This manuscript has been accepted in Annual Reviews of Plant Biology (ARPB). This version has not undergone final editing. Please refer to the final version at the ARPB.

across the spectrum, unlike multispectral images, which have defined wavelengths xii Time-of-flight (ToF) camera: device that generates quantitative three-dimensional images that extrapolate distance based on the time for emitted light to return to a detector xiv Stereography: the use of two cameras separated by a known distance to triangulate the depth of an object based on the perceived image shift between the two cameras 